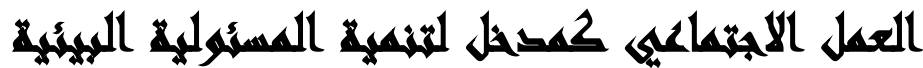

\section{لفئر سمان المناطلة العشوائية}

\section{[ᄉ]}

\author{
إبراهيم مهتدي محمد (')- أحمد مصطفى العتيق(')- مصطفى إبراهيم عَوض(') \\ ( ) معهز الدراسات والبحوث البيئية، جامعة عين شمس.

\section{المستخلم}

هدفت الدراسة الي استخدم برنامج تدخل لعمل تغير في سلوك ساكنى العشوائيات

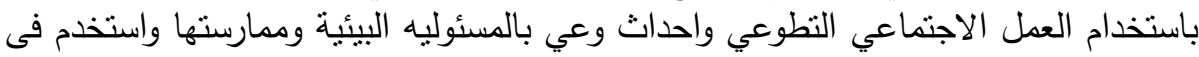

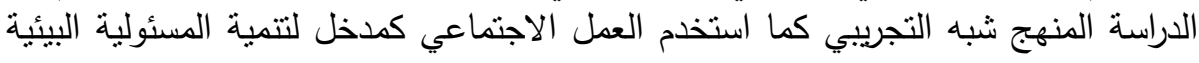

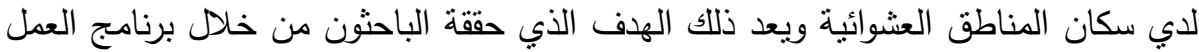

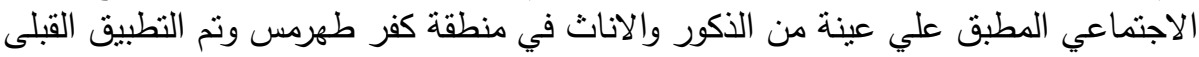

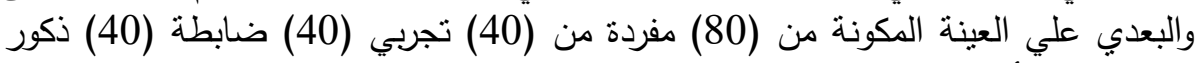

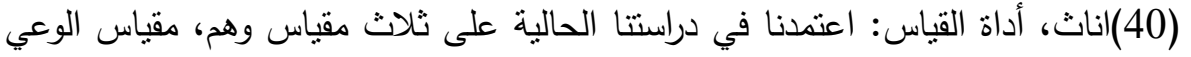

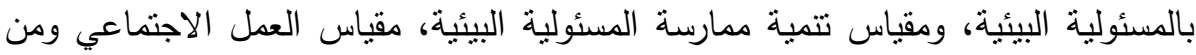

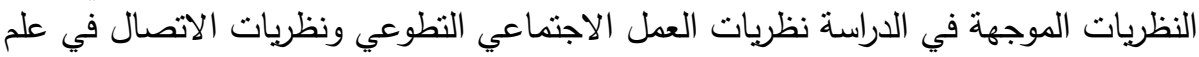

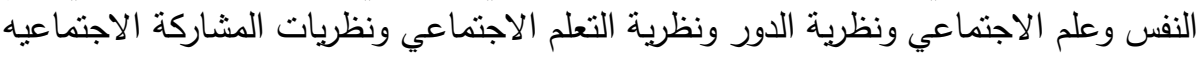

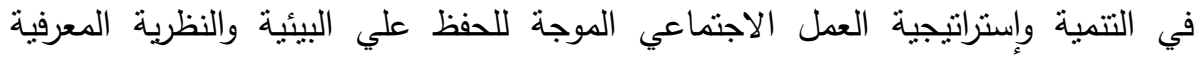

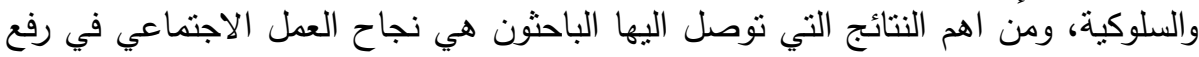

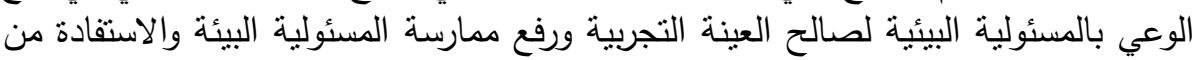

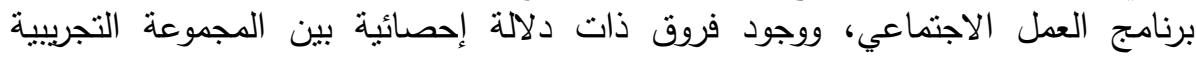

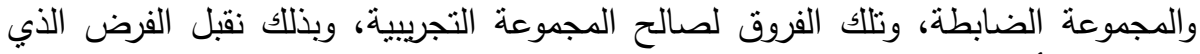

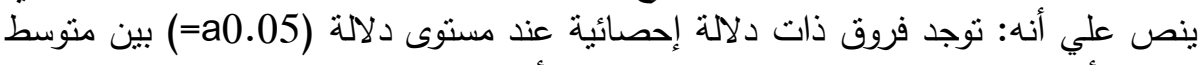

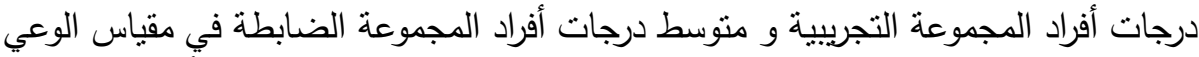

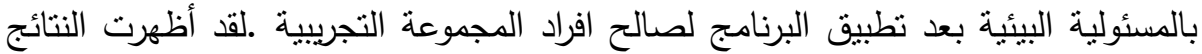

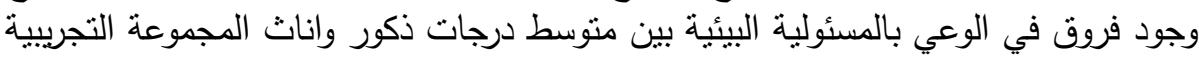

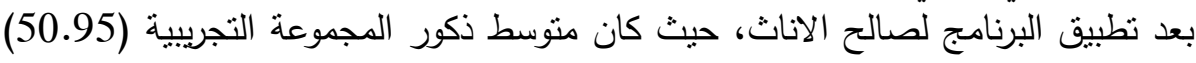
واناث المجموعة التجريبية)(60.50 ، وقيمة" ت لوناج (3.784) "عند مستوي معنوية (0.05)

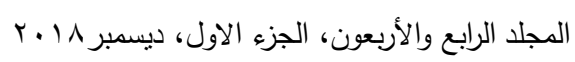


ا إتاحة الفرصة أمام مساهمات الثباب المتطوع وخلق قبادات جديدة، ووضع برنامج امتيازات وحوافز لهم. لهام r. تشجيع العمل التطوعي في صفوف الثباب مهوا كان كان حجمه أو شكله أو نوعه، وتطوير القوانين والتشريعات المنظمة لهي له. r. أن تمارس المدرسة والجامعة والمؤسسة الدينية والجئية والجمعيات الاهلية والاندية ومراكز الثباب

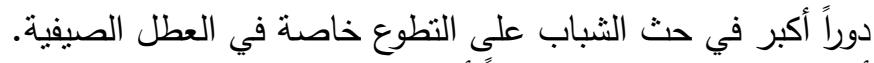
ـ. أن تمارس وسائل الإعلام دوراً أكبر في دعوة النطاب فاصة في المونين إلى العمل التطوعي.

\section{مهند}

لقد خلق اله عز وجل الإنسان وهيأ له أسباب الحياة فى الدنيا، ومهد له من كل شئ

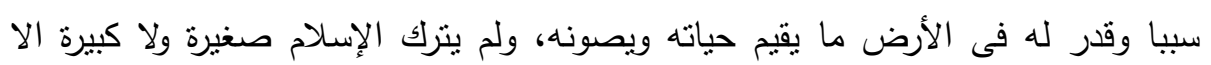

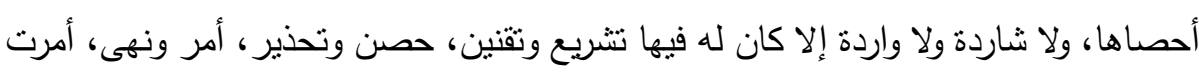

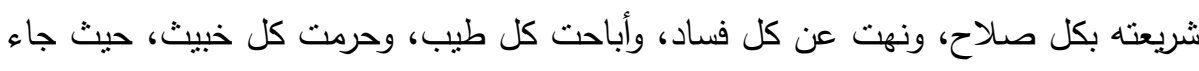

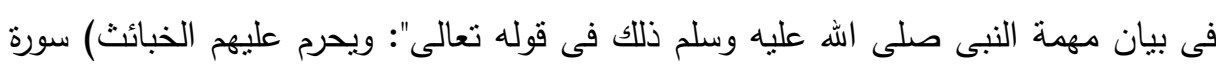

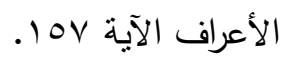

منذ أن خلق إله سبحانه وتعالى الإنسان على سطح الأرض، وهو يتعامل مع البيئة يؤثر

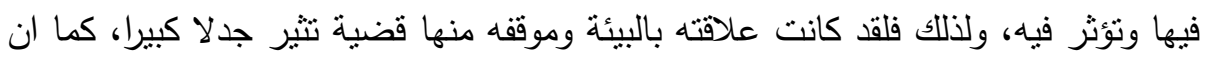
طرح القضية بأبعادها الثنائية اى البيئة مقابل الإنسان، أو الإنسان مقابل البيئة، لم تعد ملائمة

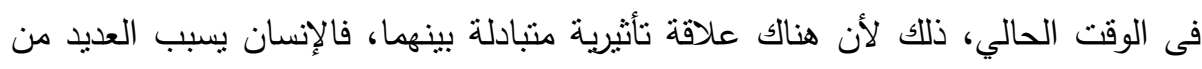

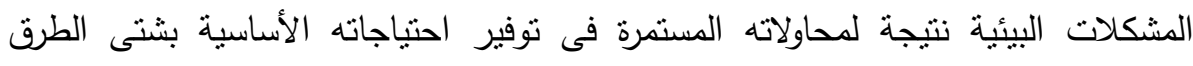
والوسائل وبدون دراسة مستفيضة لتأثبر ذلك على البيئة، ونتيجة لذلك تعرضت البئية البيئة للعديد

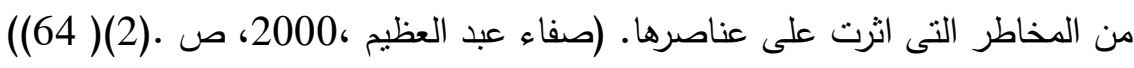

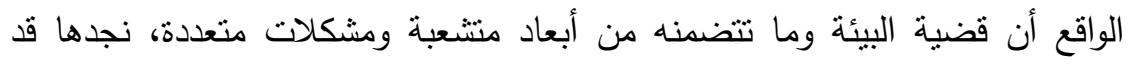
طرحت نفسها فى العقدين الأخيرين كواحدة من أخطر القضايا فى العصر الحديث إن لم تكن أخطرها على الإطلاق. 
أصبحت مشكلة تلوث البيئة خطراً لايهدد الجنس البشرى وحده بالزوال وانما يهدد كل

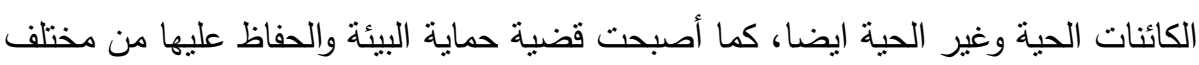
أنواع التلوث واحدة من أهم قضايا العصر أيضاً، وموضوعا حيويا فى أى تصور لبناء

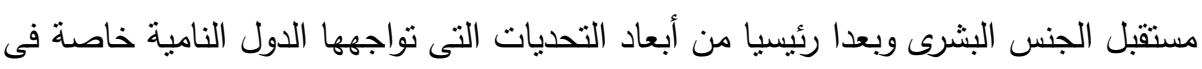

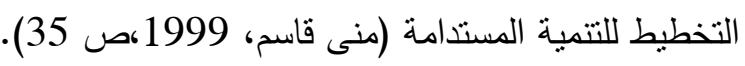
التلوث البيئى ظاهرة عالمية واكبت التقام العلمى، حتى انها شملت الدول النامية والمتقدمة ايضا ولكن مع اختلاف نوعية التلوث. لقد برزت بوضوح فى كل هذه الصور التى تلتقط كل يوم بل كل لحظة لسكان المناطق

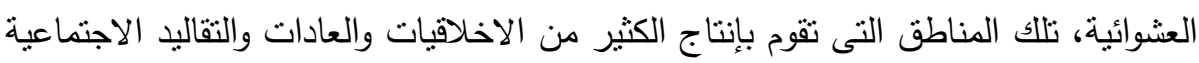

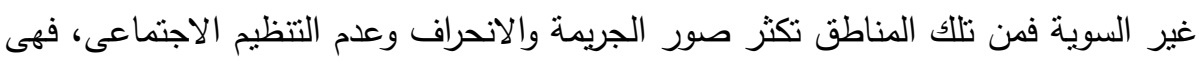
حضانات لجميع الأمراض الاجتماعية من فقر وبطالة واغتراب وجريمة وعدم تكيف. وبالنظرة

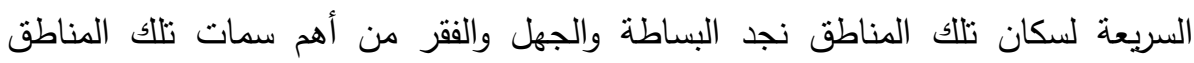

على الرغم من الجهود المضنية التى تبذلها الدولة لمحاربة الجهل والأمية نجد أن الجهل

$$
\text { والأمية سمة من أهم سمات تلاك المناطق العشوائية. }
$$

لو قلنا مثنلا تخلف الثعوب يتمثل فى الجهل والفقر والمرض فإن هذا المثل يرتكز بشكل

$$
\text { كبير فى المناطق العشوائية. }
$$

من ثم ينفرد موضوع المناطق العشوائية وآثارها السلبية بدراسة مستقلة تتطلع لوجود حل يتصدى لكل هذه الآثار التى وصلت سلبياتها الى مجالات مختلفة فوجدنا للمناطق العشوائية

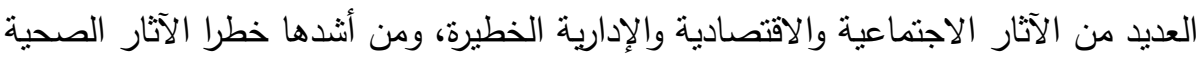

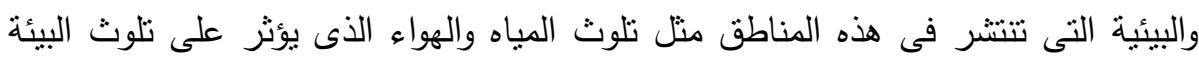

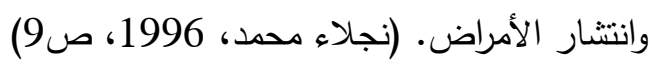

كما تعثبر المناطق محاضن للجراثيم تتنقل فيها العدوى بين سكانها بسرعة وسهولة نتيجة

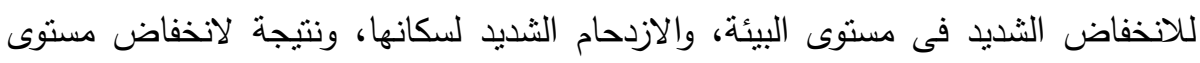

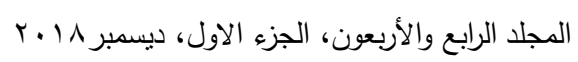


الدخل وكثرة عدد الافراد فى الأسرة فى مساكن ضيقة، وعدم وجود شوارع مناسبة فانتشرت

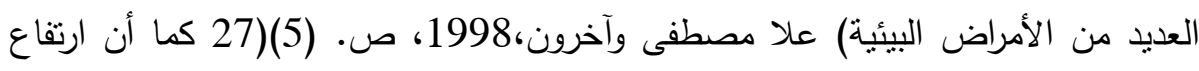

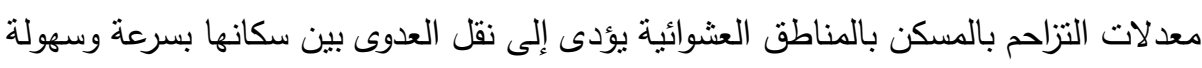

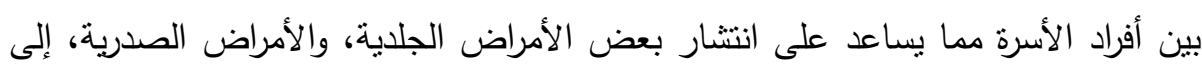

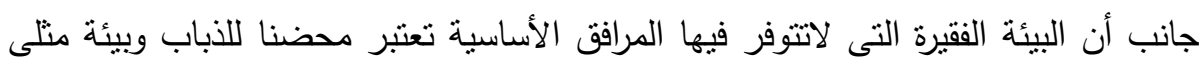
لتكاثره نتيجة لوجود الفضلات الآدمية وروث الحيوانات فى الأزقة والحارات وانتشار أكوام القمامة. (المرجع السابق: ص (6) (27)).

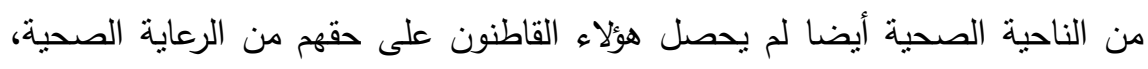

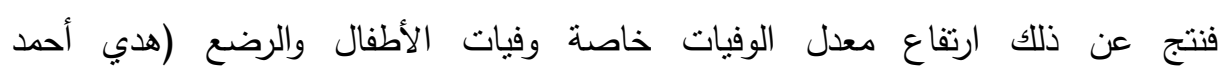

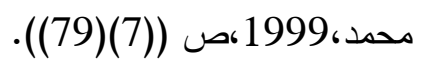

يوصف التلوث بأنه الوريث الذي حل محل الأوبئة أو المجاعات، ولذلك فقد طغي علي

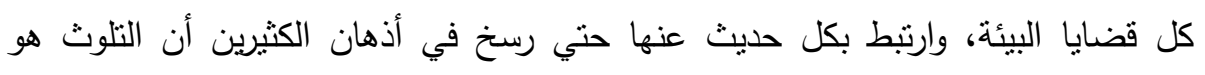

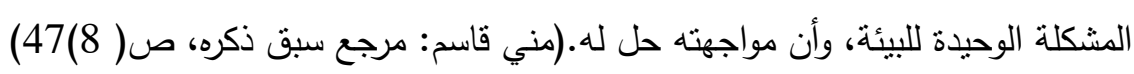

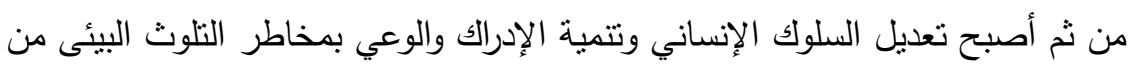

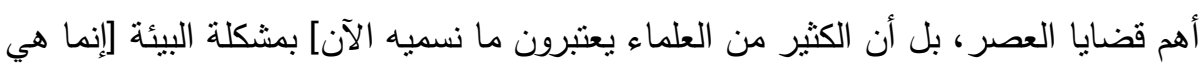

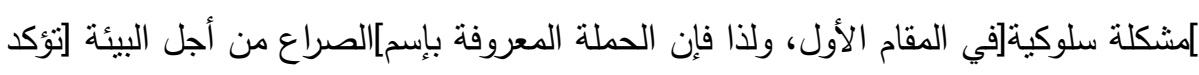

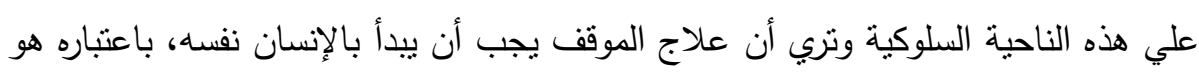

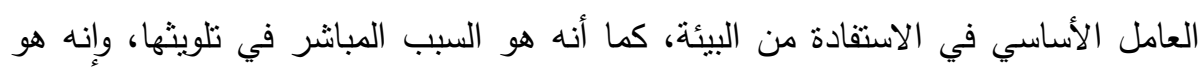
الذي يعاني من التلوث في آخر الآمر • (محمد نجيب ، 1987صن العينه (9) (25))

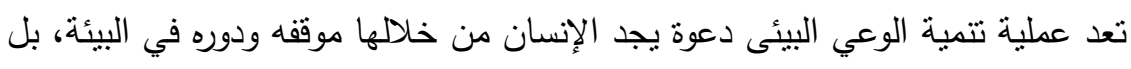

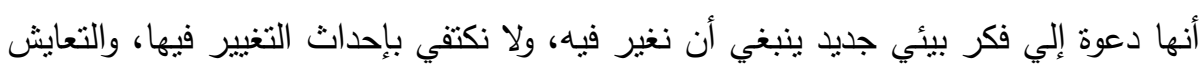

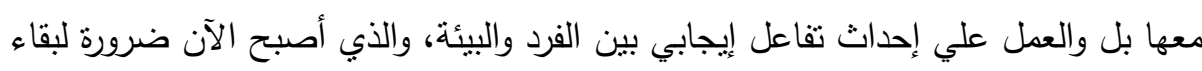

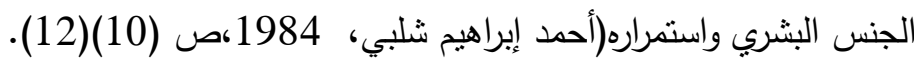
نظراً لخطورة هذه المشكلة علي الإنسان وممنلكاته وعلي الكثبر من الأنظمة البيئة السائدة، فقد حظيت بالاهتمام والدراسة. 


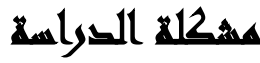

إن قضية البيئة وما تتضمنه من أبعاد متشعبة ومشكلات متعددة، نجدها قد طرحت نفسها فى العقدين الاخيرين كواحدة من اخطر القضايا فى العصر الحديث إن لم تكن اخطرها

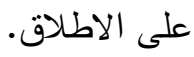

وأصبحت مشكلة تلوث البيئة خطراً لايهدد الجنس البشرى وحده بالزوال، وإنما يهدد كل الكائنات الحية وغير الحية ايضا ومن ثم أصبح تعديل السلوك الإنساني وتتمية الإدراك لكاتك

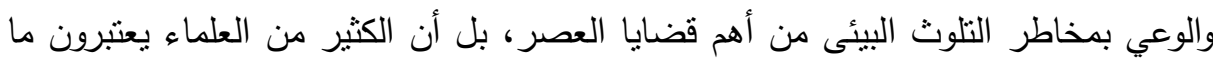

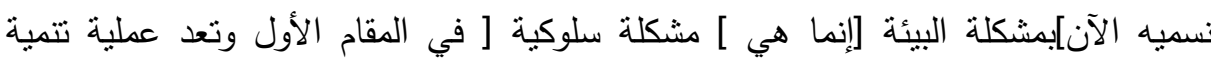
الوعي البيئى دعوة يجد الإنسان من خلالها موقفه ودوره في البيئة

لذا نجد أن العمل الاجتماعى يهتم بتتظيم سكان المجتمعات لخدمة أنفسهم، خاصة وأن

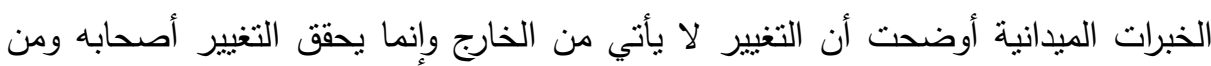

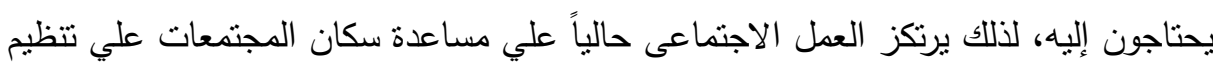

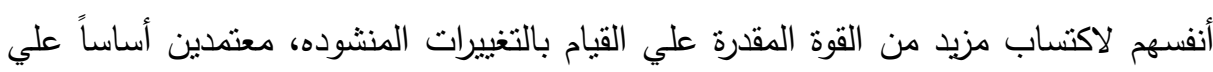

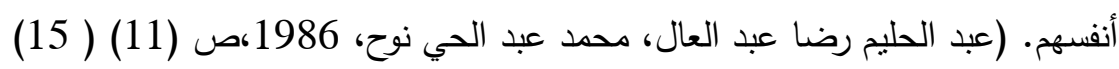
لذا تتحدد مشكلة الاراسة الحالية في محاولة الإجابة عن التساؤل الرئيسي التالي: إلى أى أى

مدى يعد العمل الاجتماعى مدخل لتتمية المسئولية البيئية لدى سكان المناطق العشوائية؟ من هذا التساؤل يمكن طرح الأسئلة الفرعية التالية: ا. ما فاعلية برنامج للعمل الاجتماعي فى تتمية المسئولية البيئية لاى سكان المناطق

$$
\text { العشوائية؟ }
$$

r. هل يختلف مستوى المسئولية البيئية باختلاف السن لدى سكان المناطق العشوائية؟

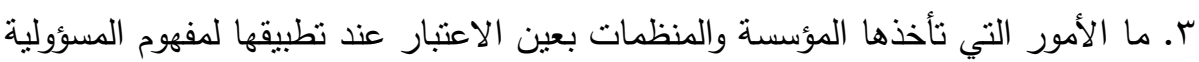
البيائية؟

ع. ما حجم العائد المتوقع للبيئية من خلال تبنيها للوعي بالمسؤولية البيئية؟

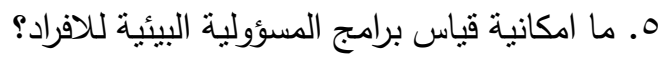

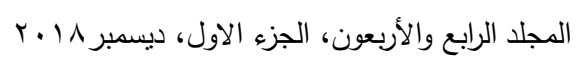


7. ما مدى تبني مؤسسات المجتمع المدني لمفهوم وممارسة المسؤولية اليبئية؟

\section{أهساهيم التراسما}

هافت الدراسة إلي تحقيق هدف رئيسي مؤداه: "التعرف علي أثز عائد التنخل للعمل

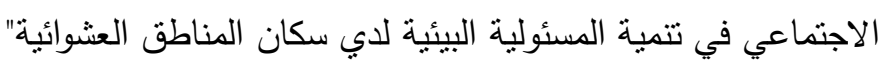
ينبثق من الهدف الرئيسي عدة أهداف فرعية: • التعرف علي أثر عائد التذخل للعمل الاجتماعي وتتمية الوعي البيئي لاي سكان فرية: المناطق العشوائية • التعرف علي اثز عائد التنخل للعمل الاجتماعي وزيادة اهتمام سكان المناطق العشوائية

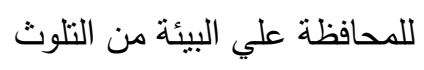

• التعرف علي أثر عائد التذخل للعمل الاجتماعي وزيادة معدل مشاركة سكان المناطق

$$
\text { العشوائية في الحفاظ علي البيئة من التلوث }
$$

\section{أهمية القورسمة}

ترجع أهمية الدراسة الراهنة إلي ما يلي: الأهمية النظرية: تبدو الأهمية النظرية لهذه الدراسة في محاولة لإضفاء المزيد علي التراث

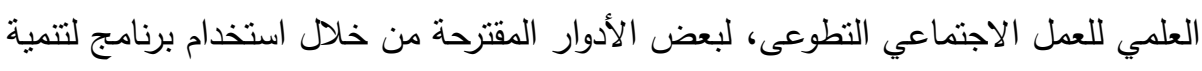
المسئولية البيئية لدي سكان المناطق العشوائية. الأهمية العملية: تبدو الأهمية العملية لهذه الدراسة في محاولة التعرف علي أثر استخدام عائد برنامج علي تتمية المسئولية البيئية لدي سكان المناطق العشوائية، والوقوف عليه لهي أهم المشكلات التي تواجه سكان تلك المناطق. الأهمية المجتمعية: نكمن الأهمية المجتمعية لهذه الدراسة في إثارة الاهتمام الخاص من المنظمات والهيئات والمؤسسات الموجودة داخل مجتمع الدراسة بخطورة مشكلات التلوث البيئي

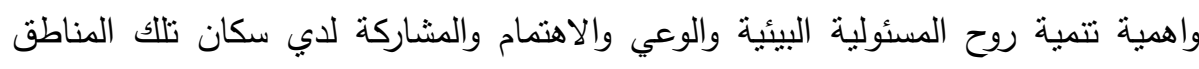

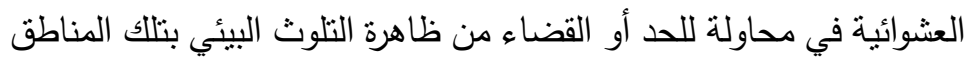




\section{هزوخ القواسمة}

أولاً: توجد فروق ذات دلالة إحصائية عند مستوى دلالة (a=0.05) بين منوسط درجات أفراد المجموعة التجريبية ومتوسط درجات أفراد المجموعة الضابطة في مقياس الوعي بالمسئولية البيئية بعد تطبيق البرنامج لصالح افراد المجموعة التجريبية ثانياً: نوجد فروق ذات دلالة إحصائية عند مستوى دلالة (a=0.05) بين منوسط درجات أفراد المجموعة التجريبية ومتوسط درجات أفراد المجموعة الضابطة في مقياس تتمية ممارسة المسئولية البيئية بعد تطبيق البرنامج لصالح افراد المجموعة التجريبية ثالثاً: نوجد فروق ذات دلالة إحصائية عند مستوى دلالة (a=0.05) بين منوسط درجات أفراد المجموعة التجريبية و متوسط درجات أفراد المجموعة الضابطة في مقياس العمل الاجتماعي بعد تطبيق البرنامج لصالح افراد المجموعة التجريبية رابعاً::توجد فروق ذات دلالة إحصائية عند مستوى دلالة (a=0.05) بين متوسط درجات ذكور واناث المجموعة التجريبية في مقياس الوعي بالمسئولية البيئية بعد نطبيق البرنامج لصالح

خامساً: نوجد فروق ذات دلالة إحصائية عند مسنوى دلالة (a=0.05) بين منوسط درجات

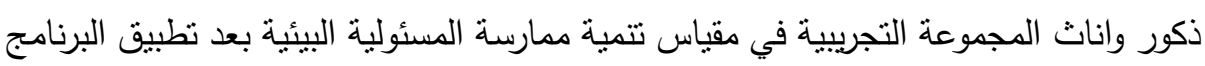
لصالح الإناث سادساً: توجد فروق ذات دلالة إحصائية عند مستوى دلالة (a=0.05) بين منوسط درجات ذكور واناث المجموعة التجريبية في مقياس العمل الاجتماعي بعد تطبيق البرنامج لصالح

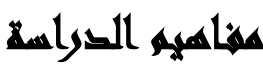

السكن العشوائى: يقصد بالسكن العشوائى " بأنه ظاهرة نمو الأسكان الثعبي الحر وذلك

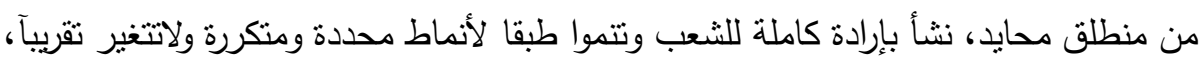

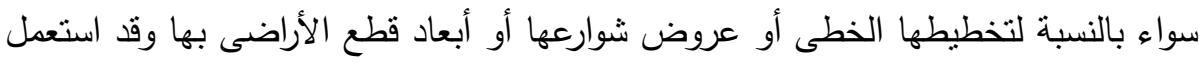

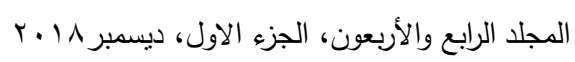


التعبير الغير رسمى لكونه بدون ترخيص ويمكن تعريف السكان العشوائى على أنه "نمو

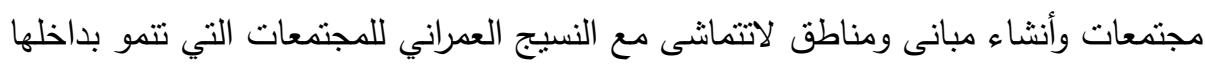

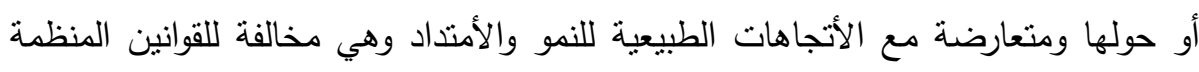
للعمران التعريفات نجد ان الأسكان العشوائى يقوم بتخطيطة وتتشيدة الأهالى بأنفسهم على الأراضى

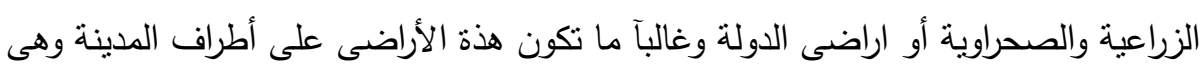

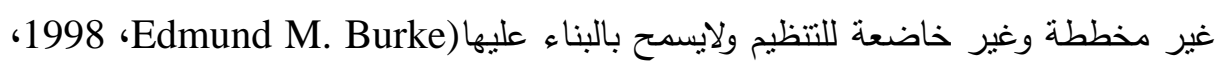
pp. $287-294)(13)$

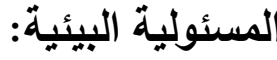

• عرفها Grob1995 على انها العبء الملقى على كاهل الفرد كى يؤدى الى ترقية البيئة

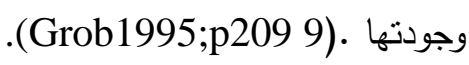
• عرفها ابرو وآخرون(1999)على انها الوعى الفردى الذى يؤثر فى البيئة ويتاثر (Ebreo etl;1999;p475) برون • عرفها kplan كابلان 2000على انها درجة الاهتمام والفهم والمشاركة للفرد نحو البيئة

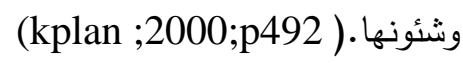

• مفيدة هلال ابراهيم (2007) عرفتها: هى قدرة الفرد على اتخاذ قرار تحمل مسئولية البيئة بما لديه من وعى واتجاه بوازع من ضميره وتعاونه مع الآخرين فى الاهنمام بالبيئة

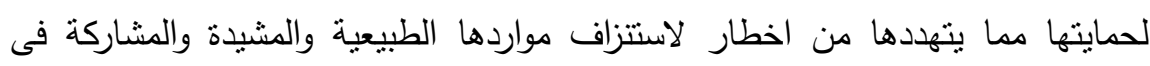

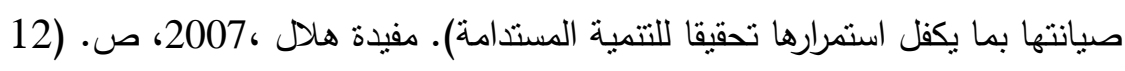

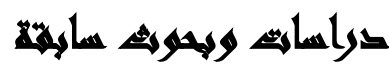

يعرض الباحثون بعض إسهامات الدراسات السابقة: • دراسة سوسن فايد(2009): الأمن النفسي للمواطن المصري مسئولية اجتماعية . حاولت الدراسة التعرف على ما يعنيه المواطن المصري من نقص الإحساس بالأمن النفسي وتناولت الاراسة الفوضى وضعف تطبيق القانون، الفساد واستغلال النفوذ، مناقثنة 
ظاهرت العنف الاجتماعي والسياسي وقت اعتمدت الدراسة على الأسلوب الإحصائي في اختيار العينة وفي أسلوب سحبها وفي جمع البيانات وتحليلها.

• دراسة سناء مبروك(2009): بعنوان المسئولية الاجتماعية والمواطنة دراسة وفئة انثرويولوجية لقيم الولاء والانتماء في شمال سيناء ـوهدفت الدراسة إلي التعرف عن

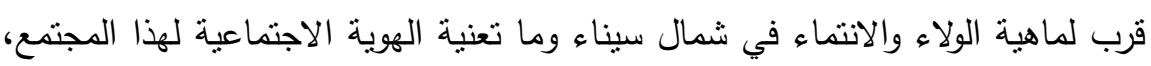
إلي جانب إلقاء الضوء علي ما يتطلبه تحقيق قيم الولاء والانتماء من تحديد المسئولية الاجتماعية للاولة ممثلة في أجهزتها التتفيذية، واعتمدت الدراسة علئه على منهج البحث الأنثروبولوجى الذي يعتمد على الطرق والأساليب الكيفية في الوصف التحليلي للظواهر الاجتماعية وعلاقتها بمتغيرها من الظواهر داخل المجتمع كما اعتمدت على إجراء المقابلات المتعمقة مع أعضاء المجتمع، والاستعانة بالملاحظة. • دراسة سهير صفوت عبد الجيد(2010): بعنوان المسئولية الاجتماعية للشباب في حماية الأمن الثقافي والاجتماعي للمجتمع، وهدفت الدراسة الى: التعرف على طبيعة الثخصية الثابة المسئولة .تثخيص واقع الثباب وانعكاسات سياسات العولمة عليهر

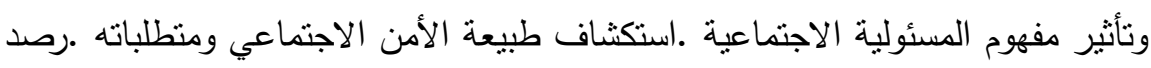

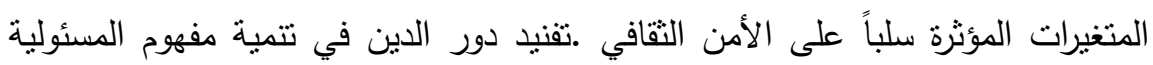
الاجتماعية فروض الدراسة، من المحتمل وجود علاقة طردية بين التفاعلات الأسرية

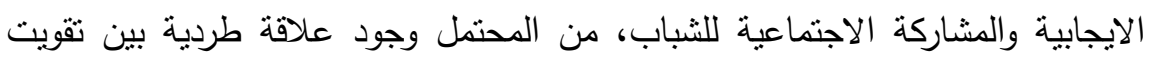
الأمن الوظيفي للشباب وضعف الإحساس بالمسئولية الاجتماعية في حماية الأمن الاجتماعي. من المحتمل وجود علاقة إيجابية من تتنتيت الهوية ونمو أطياف من التعصب المهدد

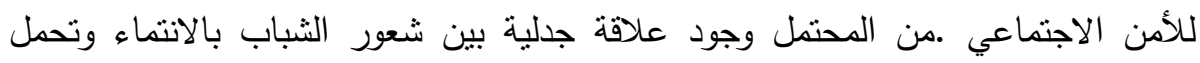
مسئولية حماية الأمن الثقافي والاجتماعي للمجتمع. تستعين الدراسة بمنهج دراسة الحالة لما لهذا المنهج من قدرة على الدئه الدراسة بعمق وتقديم

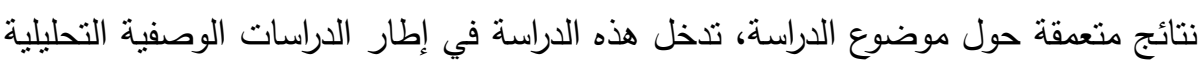

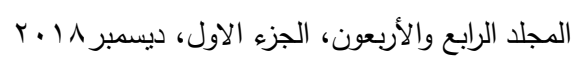


التي تسعى نحو تقرير وتحليل دور الثباب في حماية الأمن الاجتماعي والثقافي وانعكاس

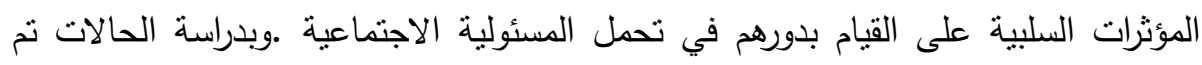

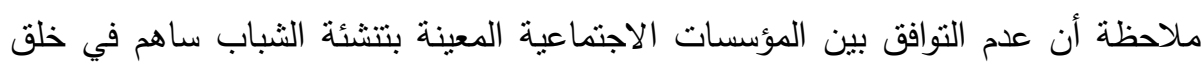

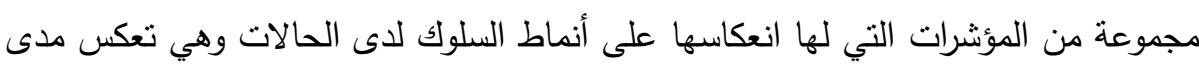

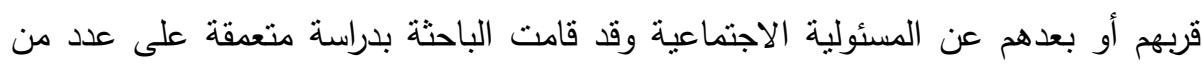
الحالات قوامهم) ثلاثون حالة (بواقع عثرة حالات لكل منطقة من مناطق الدراسة ومقسمة

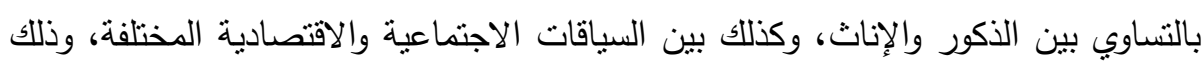
من خلال دليل مقابلة مفتوح يتيح للحالة الحديث بحرية في الإدلاء برأيه. • دراسة هبه الله خاطر 2007: المسئولية الاجتماعية وعلاقتها بالفعالية الذاتية ووجهة الضبط والمشاركة السياسية لاي المرأة العاملة. هدفت الاراسة إلي التعرف علي العلاقة بين المسئولية الاجتماعية وكل من الفعالية

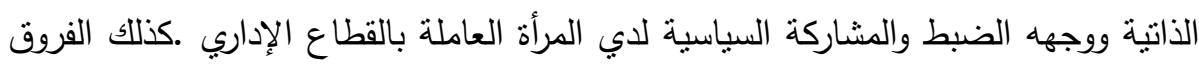

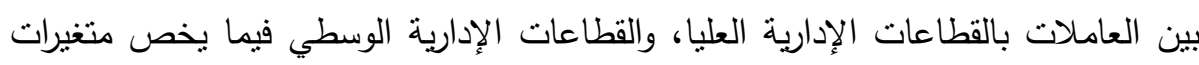

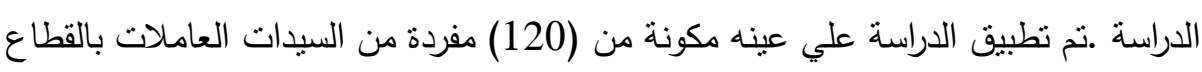

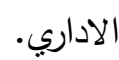
في المجتمع المصري، تتراوح أعمارهن من (59-43) سنه منهن (60) إمرأه متزوجة تعمل بالقطاعات الإدارية العليا، (60) إمراه منزوجة تعمل بالقطاعات الإدارية الوسطي.

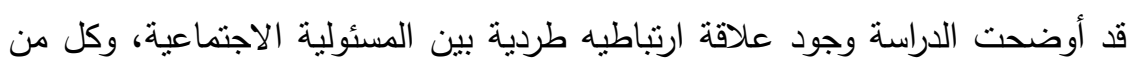

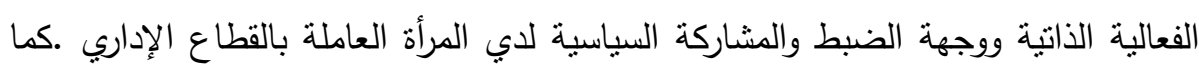

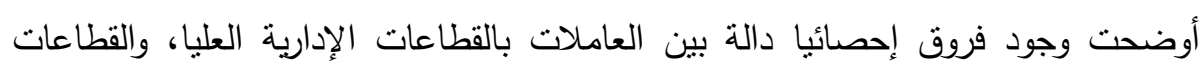

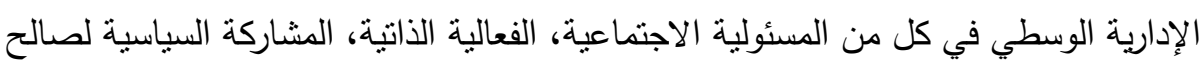
العاملات بالقطاعات الإدارية العليا. 


\section{• دراسة حسام صدقي أبو زيد 2001 عن المسئولية الاجتماعية بين التنشئة} الوالديه ويعض سمات الثخصية.

هدفت الدراسة إلي الكثف عن العلاقة بين المسئولية الاجتماعية وعلاقتها ببعض أساليب التتشئة الاجتماعية مثل التبعية - الاستقلال - التذبذب -الاتساق -الرفض -التقبل سمن قبل التبل الأب .والعلاقة بين المسئولية الاجتماعية وبعض سمات الثخصية .وقد أسفرت الدراسة عن أنه لا نوجد فروق ذات دلالة إحصائيا في المسئولية الاجتماعية بين الذكور والإناث .لكن توجد فروق ذات دلالة إحصائيا في المسئولية الاجنماعية بين الريفيين والحضريين لصالح

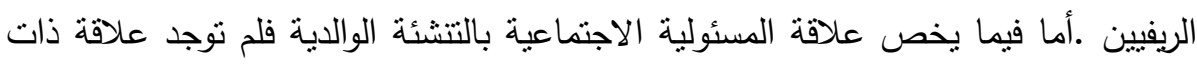

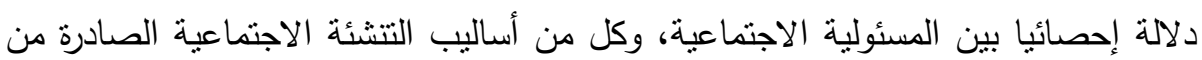

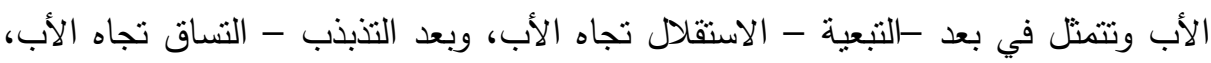

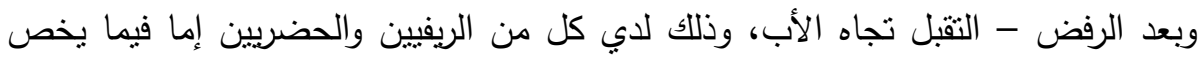
علاقة المسئولية الاجتماعية ببعض سمات الثخصية، فقد توصلت الدراسة إلي أنه توجد الثد فروق ذات دلالة إحصائيا عكسية بين المسئولية الاجتماعية وكل من وجهه الضبط وسمات الشخصية في بعد الذهنية - الواقعية وبعد الانبساط -الانطواء لدي كل من الحضريين والريفيين بصفه عامة. النظريات المستخدمة في الدراسة: • تبنـى نظرية الدور على خمس افتراضات أساسية، يوجد عليها اتفاق عام بين العلوم

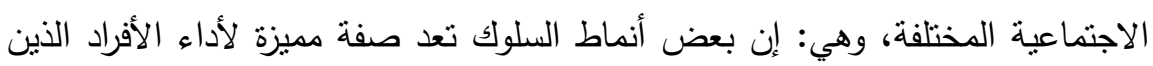

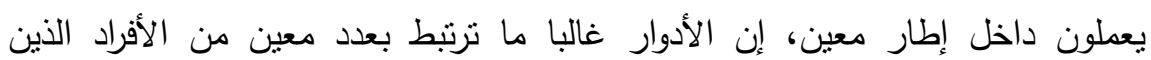

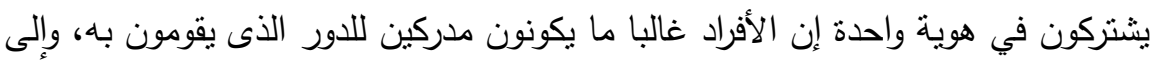

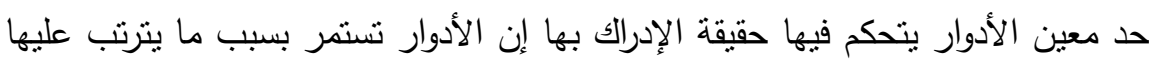

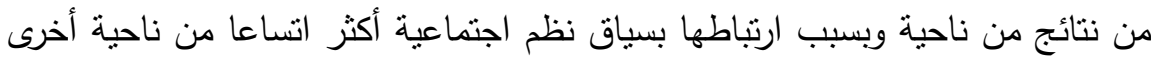

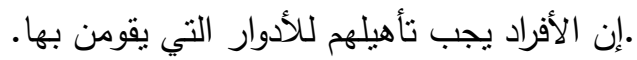


• نظرية التعلم بالملاحظة في الوقت الحاضر : إن تصور باندورا للتعلم بالملاحظة هو أحد مكونات نظريته في التعلم الاجتماعي، ويقوم في الوقت الحاضر بتوضيح نظرية شاملة وموحدة للسلوك الإنساني، كما يحاول إحداث تفسير رئيس لمجالات واسعة من مجالات

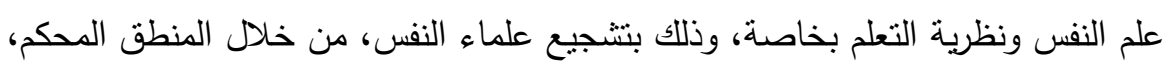

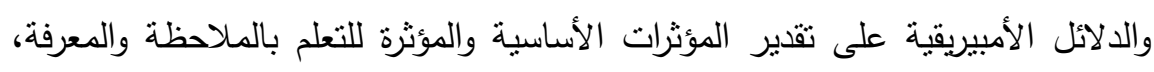

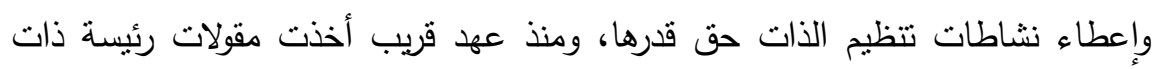

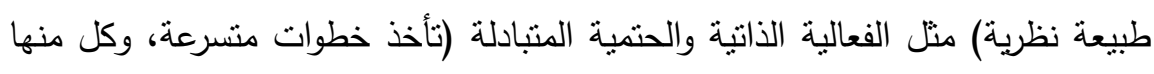

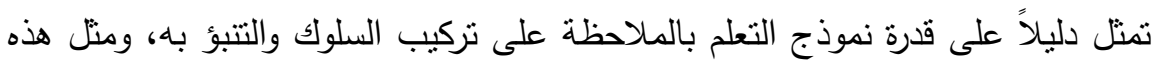

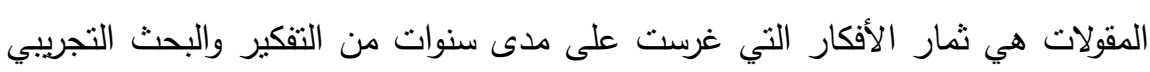

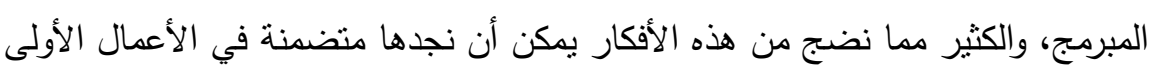
المتعلقة بظواهر التعلم بالملاحظة. على صعيد عملي أكثر يبذل باندورا الكثير من الجهد من أجل نطبيق نظريته في مجال علم النفس الإكلينيكي والتطوري والاجتماعي، وقد أصبحت نطبيقات نظرية مبادئ التعلم

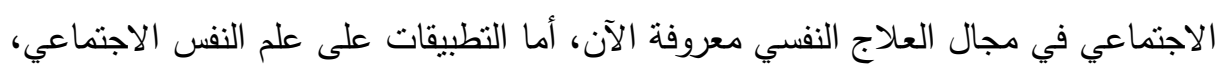

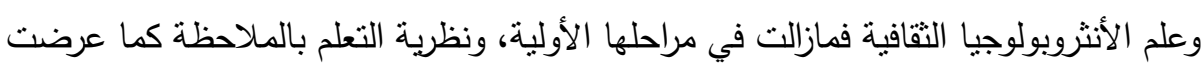

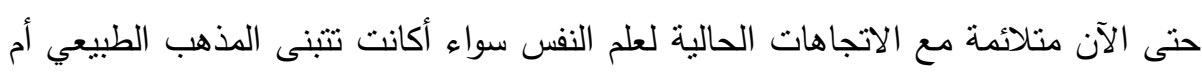

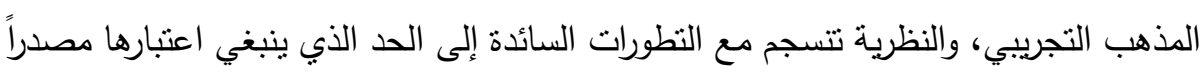

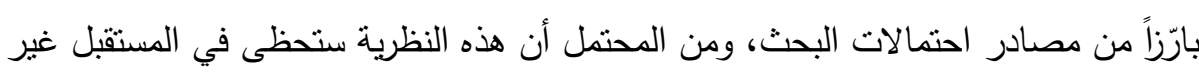

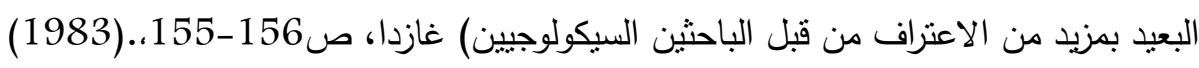

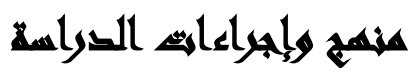

\section{أولا: نوع الاراسة: المنهج شبه التجريبي الذي اعتمدت عليه الدراسة:}

التصميمات شبه التجريبية الدقيقية:True Experimental designs هناك العديد من الطرق التي يمكن استخدامها في تصميم المجموعات التجريبية لتكون أكثر تماثلا وتكافؤا .

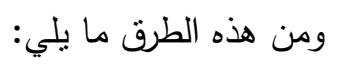


• سحب عينات المجموعات عشوائيا كلما أمكن كأفضل أسلوب للتحكم في كثير من المتغيرات .ويعني ذلك استخدام العشوائية في اختيار عينة البحث وتوزيعها في مجموعات. • استخدام طريقة المزاوجة، وهي من الطرق المعروفة لتحقيق التوازن في تصميم المجموعات، وتعني أن يقوم الباحث بتحديد عشوائي لأعضاء المجموعنين على أساس زوجي، بحيث يتفق كل فرد في خصائص محددة، ثم يتم تعيين أحدهما بالمجموعة التجريبية والآخر في المجموعة الضابطة.

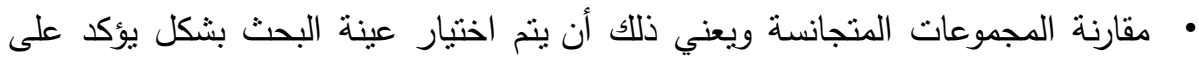
تجانس جميع المفردات حول المتغير المراد دراسته، ثم توزيعها عشوائيا بين المجموعات التجريبية والضابطة. • استخدام مفردات البحث كوسيلة تحكم في المتغيرات الخارجية، وذلك للسيطرة على الاختلاف بين الأعضاء، ويتم ذلك من خلال تعريض المجموعتين للمعالجة التجريبية في مجموعة واحدة، ثم توزيعهما في مجموعة تجريبية وأخرى ضابطة، ثم إجراء المعالجة

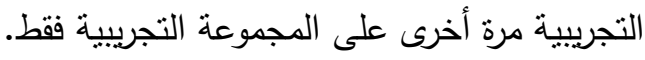
• استخدام تحليل التباين كوسيلة إحصائية لتحقيق التوازن بين المجموعات، خاصة وأنه يعتمد الوسط الحسابي كنقطة إسناد، وذللك لأنه يضبط ويعدل درجات المتغير التابع سعيا لتهيل لتلافي الفروق البيئية الناتجة عن متغيرات أخرى كالعمر أو الخبرة أو غير ذلك. أنواع تصميمات المجموعات: يتأثر التصميم التجريبي بعدد المجموعات التجريبية

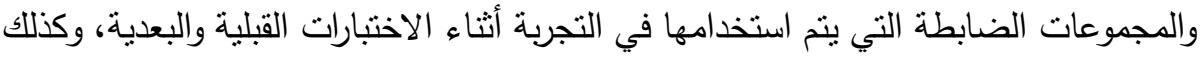
عند التحكم في المتغير المستقل. ميدان الدراسة: نم إجراء هذه الدراسة في محافظة الجيزة) كفر طهرمس (منظقة عشوائية هي منطقة سكنية تقع في محافظة الجيزة، وبالتحديد تابعة لقسم بولاق الدكرور، وهي منطقة

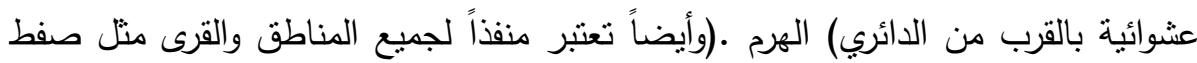

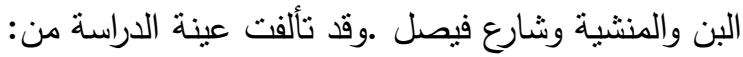


أ- العينة الاستطلاعية :أجريت هذه الدراسة الاسنطلاعية على عينة مكونة من 40 فرد من

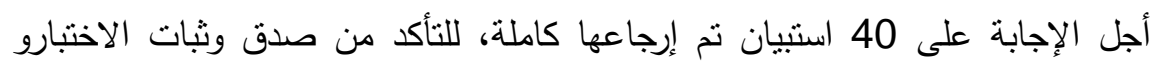
المقياس. ب- أداة القياس :اعتمدنا في دراستتا الحالية على ثلاث مقاييس وهم، مقياس الوعي بالمسئولية البيئية، ومقياس تتمية ممارسة المسئولية البيئية، مقياس العمل الاجتماعي.

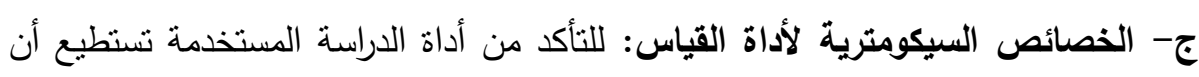
تقيس ما وضعت من أجله لتقيسه يجب قياس الخصائص السيكومترية لهذه الأداة وهذه الخصائص تتمثل في الصدق والثبات وسنتطرق إلى كيفية حساب كل خاصية من هانين الخاصيتين.

د -العينة الفعلية: تكون عينة الدراسة من مجموعتين، مجموعة تجريبية مكونة من (40)

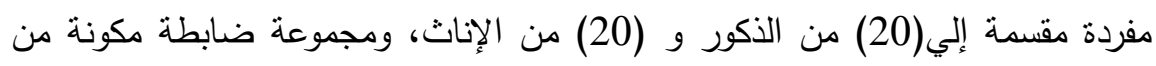

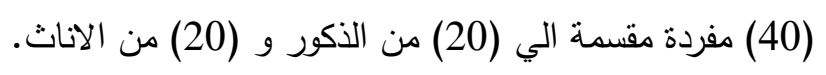

\begin{tabular}{|c|c|c|}
\hline & \multicolumn{2}{|c|}{ جدول( (): يوضح توزيع افراد العينة حسب متغير العمر } \\
\hline النسبة المئوية\%\% & العدد & العمر \\
\hline $35.0 \%$ & 28 & من 25 إلى آقل من30 \\
\hline $31.3 \%$ & 25 & من 30 إلى أقل من35 \\
\hline $27.4 \%$ & 22 & من 35 إلى آقل من40 \\
\hline $6.3 \%$ & 5 & اكثر من 40 سنة \\
\hline $100 \%$ & 80 & الاجمالى \\
\hline
\end{tabular}

من خلال استعراض الجدول رقم (1) الخاص بتوزيع أفراد عينة الدراسة حسب متغير

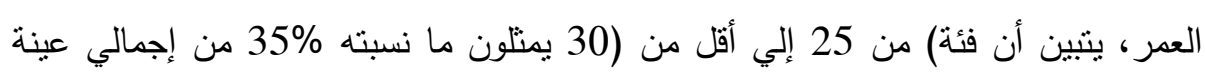

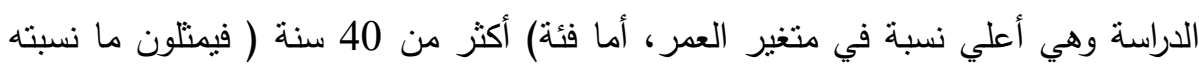
6.3\%من إجمالي عينة الدراسة وهي أقل نسبة في متغير العمر . 
جدول(Y): يوضح توزيع افراد العينة حسب متغير المستوي التعليمي

\begin{tabular}{|c|c|c|}
\hline النسبة المئوية\%\% & العدد & المستوي التعليمى \\
\hline $3.8 \%$ & 3 & يقراً ويكتب \\
\hline $5.0 \%$ & 4 & تعليم دون المتوسط \\
\hline $68.7 \%$ & 55 & مؤهل متوسط \\
\hline $15.0 \%$ & 12 & مؤهل فوق المتوسط \\
\hline $7.5 \%$ & 6 & مؤهل جامعي \\
\hline $100 \%$ & 80 & الاجمالى \\
\hline
\end{tabular}

من خلال استعراض الجدول رقم (2) الخاص بنوزيع أفراد عينة الدراسة حسب متغير

المستوي التعليمي، يتبين أن فئة) مؤهل متوسط (يمتلون ما نسبته 68.7 من من إجمالي عينة الدراسة وهي أعلي نسبة في متغير المستوي التعليمي، اما فئة) يقرأ ويكتب (فيمتلون ما نسبته فئه 3.8\%من إجمالي عينة الدراسة وهي أقل نسبة في متغير المستوي التعليمي.

جدول(ץ): يوضح توزيع افراد العينة حسب متغير الدخل الثهري إنهي

\begin{tabular}{|c|c|c|}
\hline النسبة المئويةٌ\% & العدد & الاخل الشهري \\
\hline $7.5 \%$ & 6 & آقل من10001 ج \\
\hline $65.0 \%$ & 52 & من1000اقل من2000 ج \\
\hline $17.5 \%$ & 14 & من2000 أقل من3000 ج \\
\hline $10.0 \%$ & 8 & من3000 آقل من4000 ج \\
\hline $100 \%$ & 80 & الاجمال] \\
\hline
\end{tabular}

من خلال استعراض الجدول رقم (3) الخاص بتوزيع أفراد عينة الدراسة حسب متغير

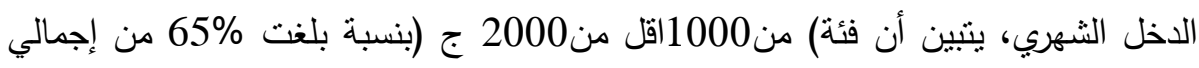

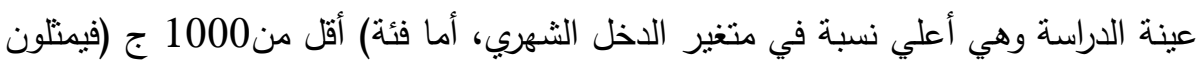
ما نسبته 7.5\% من إجمالي عينة الدراسة وهي أقل نسبة في متغير الدخل الثهري. جدول(§): يوضح نوزيع افراد العينة حسب متغير الحالة الاجتماعية

\begin{tabular}{|c|c|c|}
\hline النسبة المئويةٌ\% & العدد & الحالة الاجتماعية \\
\hline $22.5 \%$ & 18 & اعزب \\
\hline $70.0 \%$ & 56 & متزوج \\
\hline $5.0 \%$ & 4 & مطلق \\
\hline $2.5 \%$ & 2 & أرمل \\
\hline $100 \%$ & 80 & الإجمالى \\
\hline
\end{tabular}


من خلص استعراض الجدول رقم (4) الخاص بتوزيع أفراد عينة الدراسة حسب متغير

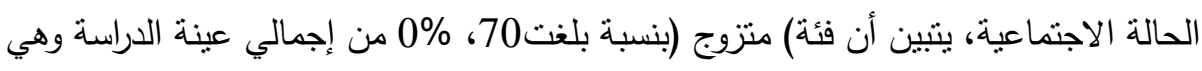

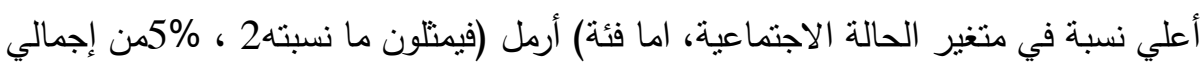
عينة الدراسة وهي أقل نسبة في متغير الحالة الاجتماعية.

\begin{tabular}{|c|c|c|}
\hline النسبة المئويةه\% & 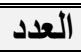 & خبرة العمل الاجتماعى \\
\hline $20.0 \%$ & 16 & لاعل اعل \\
\hline $75.0 \%$ & 60 & آقل من 5 سنوات \\
\hline $5.0 \%$ & 4 & 10سنوات فما اكثز \\
\hline $100 \%$ & 80 & الإجمالى \\
\hline
\end{tabular}

من خلا استعراض الجدول رقم (5) الخاص بتوزيع أفراد عينة الدراسة حسب متغير خبرة العمل الاجتماعي، يتبين أن فئة) أقل من 5 سنوات ( بنسبة بلغت

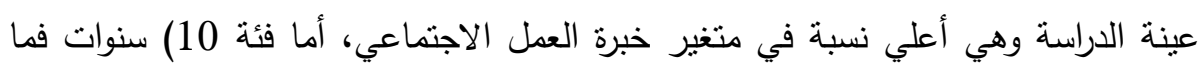

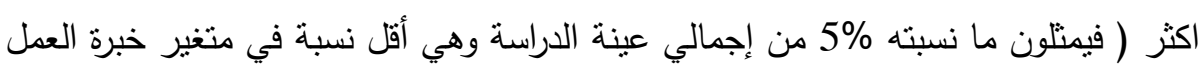
الاجتماعي). تصميم أداة الدراسة: قام الباحثون بصياغة أولية لعبارات المقياس المستخدم انطلاقا من

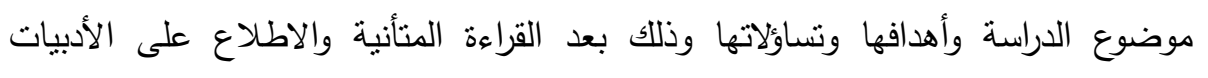

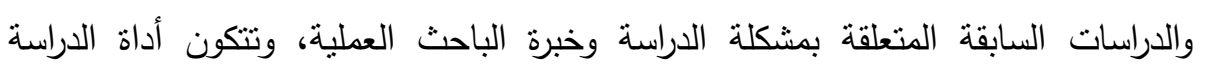
من:الجزء الأول :ويشمل البيانات الشخصية. الجزء الثاني: ويشمل عبارات مقياس الوعي بالمسئولية البيئية ويبلغ عدد عباراته 28 عبارة. الجزء الثالث: ويشمل عبارات مقياس تتمية ممارسة المسئولية البيئية ويبلغ عدد عباراته عبارة. الجزء الرابع: ويشمل عبارات مقياس العمل الاجتماعي ويبلغ عدد عباراته 30 عبارات مقسمة

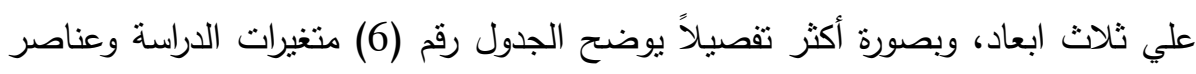
قياسها ورموز أسئلتها التي تعكسها قائمة المقياس. 
جدول(َ): بوضح متغيرات الدراسة وعناصر قباسها ورموز أسئلتها

\begin{tabular}{|c|c|c|c|}
\hline عدد العبارات & 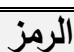 & \multicolumn{2}{|c|}{ المتغيرات } \\
\hline 28 & $\mathrm{X} 1$ & \multicolumn{2}{|c|}{ الوعى بالمسئولية البيئية } \\
\hline 50 & $\mathrm{X} 2$ & \multicolumn{2}{|c|}{ تتمية ممارسة المسئولية البيئية } \\
\hline $1-10$ & $\mathrm{X3}$ & البعد الاجتماعى & \multirow{3}{*}{ الاجنماعي } \\
\hline $11-20$ & $\mathrm{X} 4$ & بعد تنمية المهارات & \\
\hline $21-30$ & $\times 5$ & البعد البيئي & \\
\hline
\end{tabular}

حساب صدق وثبات أداة الدراسة: يشمل وصف أداة الدراسة علي صدق الاتساق الظاهري وثبات وصدق الاتساق الداخلي لأداة الدراسة وذلك على النحو التالي:

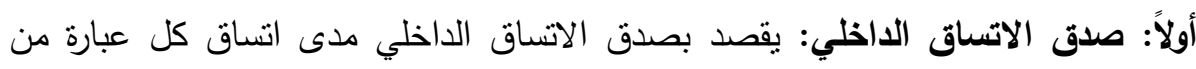

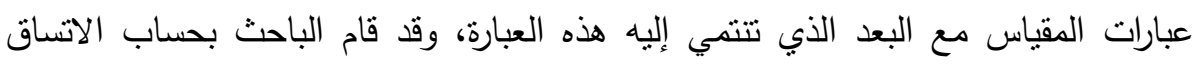

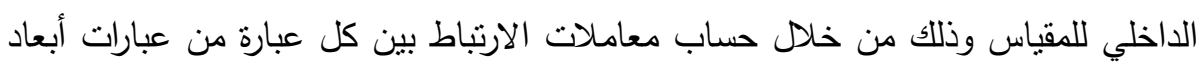
المقياس والدرجة الكلية للبعد نفسه. ثنانياً: الصدق التمييزي: ونعني به قدرة الاختبار على التمييز بين المجموعات المختلفة، أو لفور حتى الأفراد التي تقع درجاتهم على طرفي المنحنى.

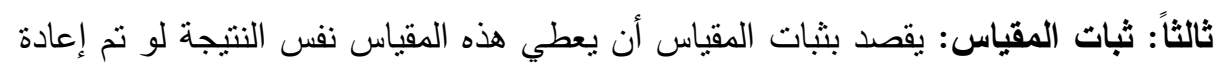

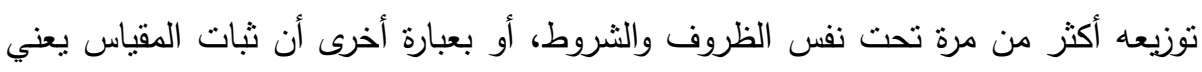
الاستقرار في نتائج المقياس وعدم تغييرها بشكل كبير فيما لو تم إعادة نوزيعها على أفراد

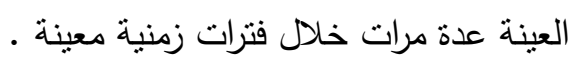

وقد قام الباحث من التحقق من صدق الاتساق الداخلي والصدق البنائي وثبات المقياس من خلال تطبيقه على عينة استطلاعية مكونة (40) فرد. رابعاً: نتائج ثبات المقياس: تحقق الباحث من ثبات استبيان الدراسة من خلادل طريقتين وهما

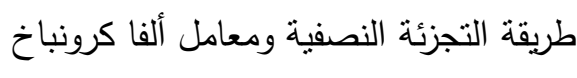
أولاً: طريقة التجزئة النصفية:Split-Half Coefficient method: تم استخدام درجات العينة الاستطلاعية لحساب ثبات المقياس بطريقة التجزئة النصفية، حيث احنسبت درجة النصف الأول لكل بعد من أبعاد المقياس وكذلك درجة النصف الثاني من الدرجات وذلك

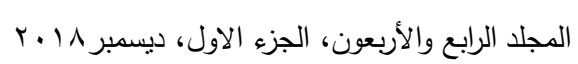


لحساب معامل الارتباط بين النصفين ثم جري تعديل الطول باستخدام معادلة سبيرمان وبراون

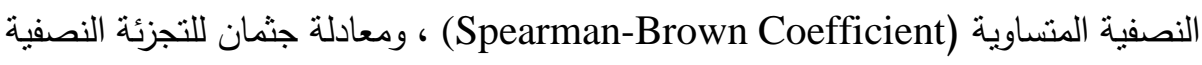
غير المتساوية (Guttman Split-Half Coefficient) والجدول رقم (7) يوضح ذللك.

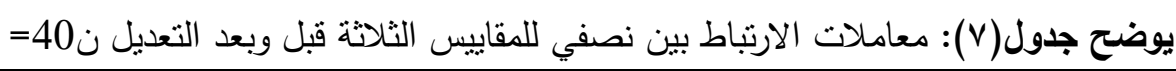

\begin{tabular}{|c|c|c|c|c|}
\hline بعد التعديل الثبات & الارتباط قبل & العبارات & البيان & م \\
\hline 0.839 & 0.722 & 28 & مقباس الوعي بالمسئولبة البينّة & 1 \\
\hline 0.986 & 0.973 & 50 & مقياس تتمبية ممارسة المسئولية البيئية & 2 \\
\hline 0.739 & 0.587 & 30 & مقياس العمل الاجتماعى & 3 \\
\hline
\end{tabular}

يتضح من الجدول السابق رقم (7) معامل الثبات للمقاييس الثلاثة، وهذا يدل على أن

المقاييس الثلاثة تتمتع بدرجة عالية جدا من الثبات بطمئن الباحث إلى تطبيقه على عينة

الدراسة.

ثانياً: :طريقة ألفا كرونياخ Alpha Cronbach :استخدم الباحث طريقة أخري من طرق حساب الثبات وهي طريقة ألفا كرونباخ، وذللك بغرض التحقق من ثابت أداة الدراسة،" ويعتمد

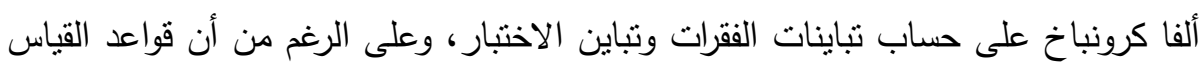
في القيمة الواجب الحصول عليها غير محددة، إلا أن الحصول على (Alpha 1 ( يعتبر معقولا، والجدول رقم (8) يوضح ثبات أبعاد المقياس باستخدام ألفا كرونباخ.

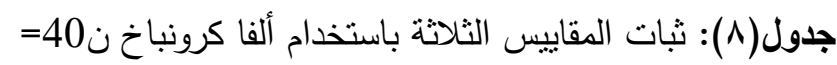

\begin{tabular}{|c|c|c|c|}
\hline معامل ألفا كرونباخ & عدد العبارات & الالبعاد & م \\
\hline 0.937 & 28 & مقياس الوعى بالمسئولية البيئية & 1 \\
\hline 0.939 & 50 & مقياس تتمية ممارسة المسئولية البيائية & 2 \\
\hline 0.953 & 30 & مقياس العمل الاجتماعى & 3 \\
\hline
\end{tabular}

أوضح الجدول السابق (8) قيم ثنات المقاييس الثلاثة والتي تراوحت بين (0.937) لمقياس الوعي بالمسئولية البيئية، و (0.939) لمقياس ممارسة المسئولية البيئية، و (0.939) لمقياس العمل الاجتماعي، وتدل مؤشرات ألفا كرونباخ أعلاه على تمتع المقاييس الثلاثة

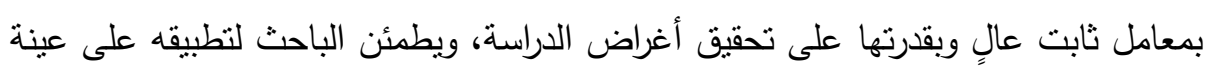


المعالِجات الِْحصائية المستخدِمة فِي الآرّاسة: لتحقيق أهداف الدراس وتحليل

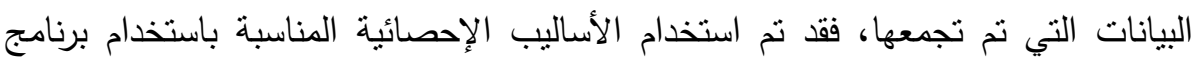

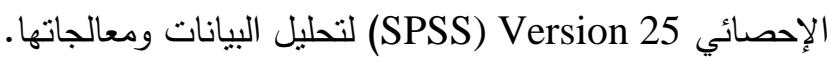
فيما يلي مجموعة من الأساليب الإحصائية المستخدمة في تحليل البيانات:

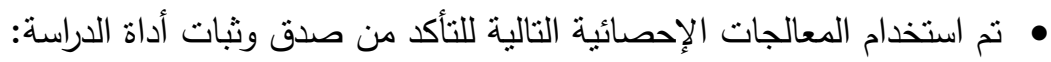

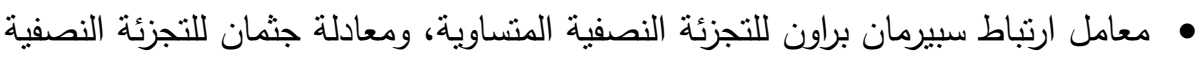
غير المنساوية، ومعامل ألفا كرونباخ : للتأكد من ثبات أداة الدراسة.

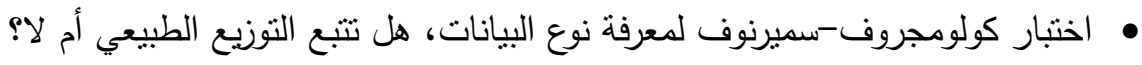
• • تم استخدام المعالجات الإحصائية التالية لتحليل نتائج الدراسة الميدانية. • تم استخدام (Independent Samples T-test) للعينتين المستقلتين.

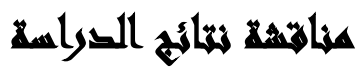

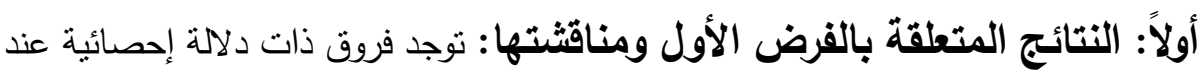

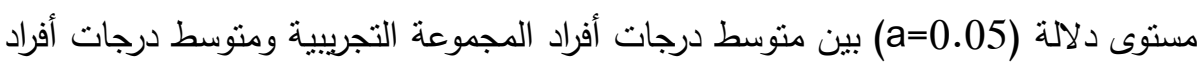
المجموعة الضابطة في مقياس الوعي بالمسئولية البيئية بعد تطبيق البرنامج لصالح الحيح أفراد المجموعة التجريبية. وللتحقق من صحة هذا الفرض تم استخدام اختبار" ت "لعينتين مستقلتين.

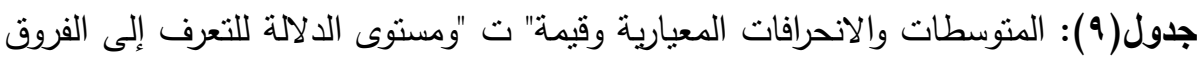

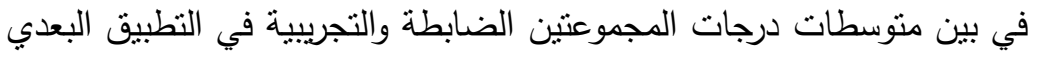
ل المقياس الوعي بالمسئولية البيئية

\begin{tabular}{|c|c|c|c|c|c|c|c|}
\hline الاستدلال & دلادتوي & قيمةt & اللمعياري & المتوسط & العدد & اللجموعة & البيان \\
\hline \multirow[b]{2}{*}{ دالة } & \multirow[b]{2}{*}{0.00} & \multirow[b]{2}{*}{10.230} & 9.243 & 55.73 & 40 & التجرييية & \\
\hline & & & 5.382 & 38.43 & 40 & الضابطة & البالمسئولية \\
\hline
\end{tabular}

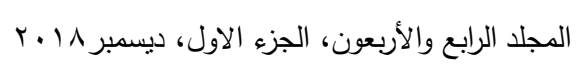


أظهرت نتائج الجدول السابق أن: قيمة" ت "المحسوبة أكبر من قيمة" ت "الجدولية في درجة

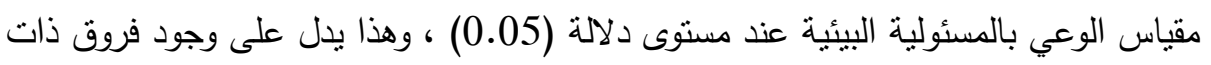

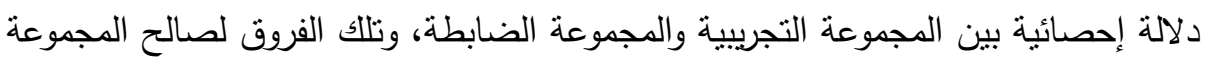

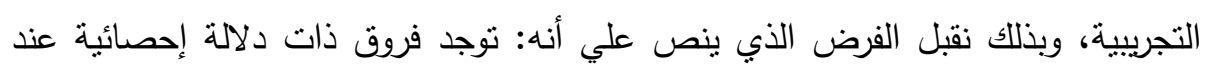
مستوى دلالة (a = 0.05) بين متوسط درجات أفراد المجموعة التجريبية ومتوسط درجات أفراد المجموعة الضابطة في مقياس الوعي بالمسئولية البيئية بعد تطبيق البرنامج لصالح افراد المجموعة التجريبية. ثانياً: النتائج المتعلقة بالفرض الثاني ومناقثتها: نوجد فروق ذات دلالة إحصائية

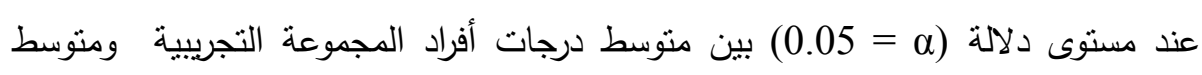

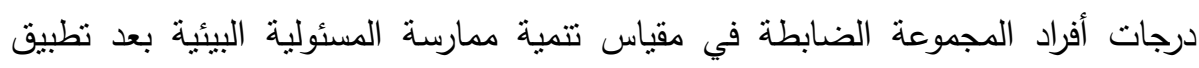
البرنامج لصالح افراد المجموعة التجريبية. وللتحقق من صحة هذا الفرض تم استخدام اختبار" ت "لعينتين مستقلتين.

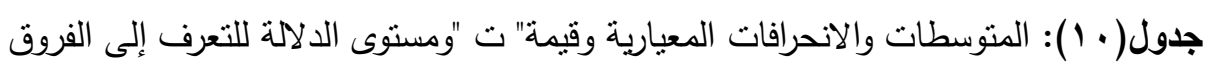
في بين متوسطات درجات المجموعتين الضابطة والتجريبية في التطبيق البعدي لمقياس تتمية ممارسة المسئولية البيئية

\begin{tabular}{|c|c|c|c|c|c|c|c|}
\hline الاستدلال & دلالة"وي & قيمة t & الالمعرافي & المتوسط & العدد & المجموعة & البيان \\
\hline \multirow[b]{2}{*}{ دالة } & \multirow[b]{2}{*}{0.00} & \multirow[b]{2}{*}{15.71} & 8.566 & 100.9 & 40 & التجريبية & \multirow{2}{*}{ مقياس تتمية } \\
\hline & & & 8.528 & 70.88 & 40 & الضابطة & \\
\hline
\end{tabular}

أظهرت نتائج الجدول السابق أن: قيمة" ت "المحسوبة أكبر من قيمة" ت "الجدولية في درجة

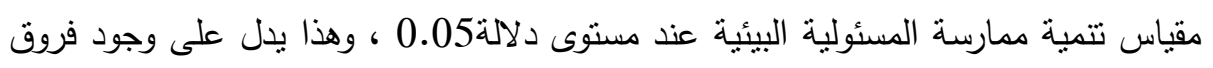
ذات دلالة إحصائية بين المجموعة التجريبية والمجموعة الضابطة، وتلك الفروق لصالح المجموعة التجريبية، وبذلك نقبل الفرض الذي ينص علي أنه :توجد فروق ذات دلالة إحصائية عند مستوى دلالة ( = 0.05) بين متوسط درجات أفراد المجموعة التجريبية 
ومتوسط درجات أفراد الهموعة الضابطة في مقياس تتمية ممارسة المسئولية البيئية بعد تطبيق البرنامج لصالح افراد المجموعة التجريبية. ثالثاً :النتائج المتعلقة بالفرض الثالث ومناقشتها: توجد فروق ذات دلالة إحصائية عند مستوى دلالة (a) = 0.05) بين منوسط درجات أفراد المجموعة التجريبية ومتوسط درجات أفراد المجموعة الضابطة في مقياس العمل الاجتماعي بعد تطبيق البرنامج لصالح أفراد المجموعة التجريبية. وللتحقق من صحة هذا الفرض تم استخدام اختبار" ت "لعينتين مستقلتين.

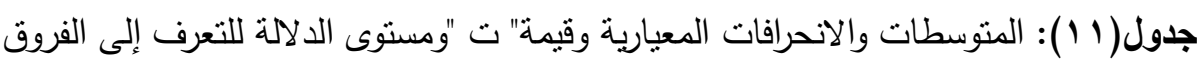
في بين منوسطات درجات المجموعتين الضابطة والتجريبية في التطبيق البعدي

\begin{tabular}{|c|c|c|c|c|c|c|c|}
\hline الاستدلال & دلالةتّوي & قيمة t & الالنحرافي & المتوسط & العدد & المجموعة & البيان \\
\hline \multirow{2}{*}{ دالة } & \multirow{2}{*}{0.000} & \multirow{2}{*}{14.472} & 9.521 & 64.98 & 40 & التجريبية & \multirow{2}{*}{ الاحتماع } \\
\hline & & & 5.535 & 39.78 & 40 & الضابطة & \\
\hline
\end{tabular}

أظهرت نتائج الجدول السابق أن: قيمة" ت "المحسوبة أكبر من قيمة" ت "الجدولية في درجة مقياس العمل الاجتماعي عند مستوى دلالة0.05 ، وهذا يدل على وجود فروق ذات دلالئة إحصائية بين المجموعة التجريبية والمجموعة الضابطة، وتلك الفروق لصالح المجموعة التجريبية، وبذلك نقبل الفرض الذي ينص علي أنه :توجد فروق ذات دلالة إحصائية عند مستوى دلالة (a = 0.05) بين متوسط درجات أفراد المجموعة التجريبية و متوسط درجات أفراد المجموعة الضابطة في مقياس العمل الاجتماعي بعد تطبيق البرنامج لصالح افراد المجموعة التجريبية. وهذا يعني فعالية البرنامج الذي تم تطبيقه علي عينة الدراسة في العمل الاجتماعي 
جدول(Y I ): نتائج اختبار" ت "لفروق بين عينتين مرتبطنين للمجموعة التجريبية، ونفسها بعد

\begin{tabular}{|c|c|c|c|c|c|c|c|c|}
\hline \multicolumn{9}{|c|}{ مرور شهر من تطبيق البرنامج } \\
\hline 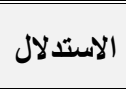 & دلالةتوي & 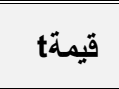 & الحرجية & الانحعراف & المتوسط & العدد & المجموعة & 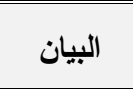 \\
\hline \multirow{2}{*}{ دالة } & \multirow{2}{*}{0.000} & \multirow{2}{*}{13.835} & \multirow{2}{*}{39} & 73.875 & 64.98 & 40 & تجرييية & \multirow{2}{*}{ الاجنماعي } \\
\hline & & & & 10 & 73.875 & 40 & تجريبية & \\
\hline
\end{tabular}

أظهرت نتائج الجدول السابق أن: لقد أظهرت النتائج أن قيمة" ت "الدحسوبة لمقياس العمل الاجتماعي كانت أكبر من قيمة" ت "الجدولية عند المستوى دلالة050.05 ، وهذا يشير إلى على إنى عدم وجود فروق ذات دلالة إحصائية بين متوسط درجات أفراد المجموعة التجريبية في القياس

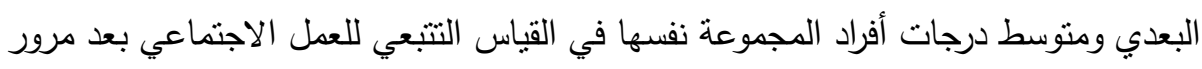
شهر من نطبيق البرنامج، حيث كان منوسط القياس البعدي (64.98) ومنوسط القياس

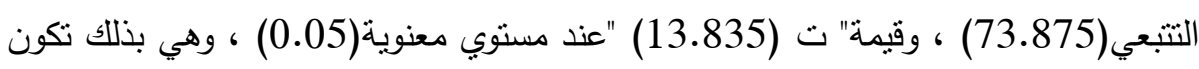

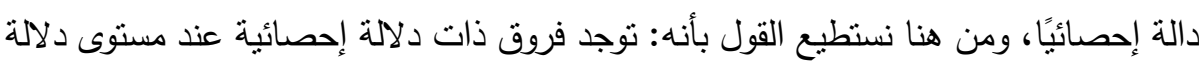

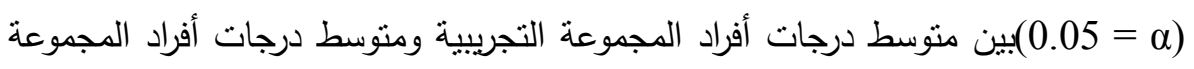
نفسها في القياسين البعدي والتنبعي على مقياس العمل الاجتماعي.

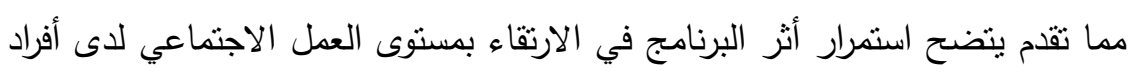
المجموعة التجريبية بعد مرور شهر من تطبيق البرنامج عليهر. عاشراً: النتائج المتعلقة بالقرض العاشر ومناقشتها: توجد فروق ذات دلالة إحصائية عند مستوى دلالة ( = 0.05) بين متوسط درجات ذكور واناث المجموعة التجريبية في القياس التتبعي على مقياس الوعي بالمسئولية البيئية لصالح الاناث. وللتحقق من صحة هذا الفرض تم استخدام اختبار" ت "لعينتين مستقلتين. 
جدول(ب ا ) : المتوسطات والانحرافات المعيارية وقيمة" ت "ومستوى الدلالة للتعرف إلى الفروق

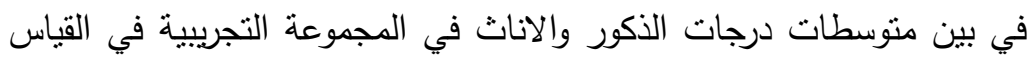
التتبعي لمقياس الوعي بالمسئولية البيئية

\begin{tabular}{|c|c|c|c|c|c|c|c|}
\hline الاستدلال & مستلوي & قيمةt & الانحرافي & المتوسط & العدد & المجموعة & البيان \\
\hline \multirow[t]{2}{*}{ دالة } & \multirow[t]{2}{*}{0.000} & \multirow[t]{2}{*}{5.446} & 6.436 & 59.55 & 20 & تنجريبية & \multirow{2}{*}{ بالمسئولية } \\
\hline & & & 8.154 & 72.2 & 20 & تتبعي اناثة & \\
\hline
\end{tabular}

أظهرت نتائج الجدول السابق أن: لقد أظهرت النتائج وجود فروق في الوعي بالمسئولية البيئية

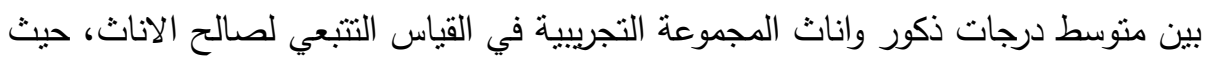
كان منوسط ذكور المجموعة التجريبية في القياس التتبعي (59.55) إناث المجموعة التجريبية في القياس التتبعي (72.20) ، وقيمة" ت (5.446) "عند مستوي معنوية (0.05) ، وهي

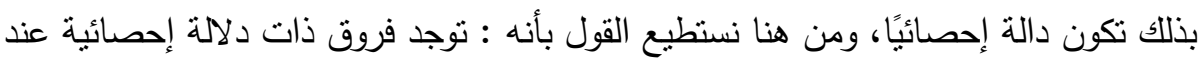

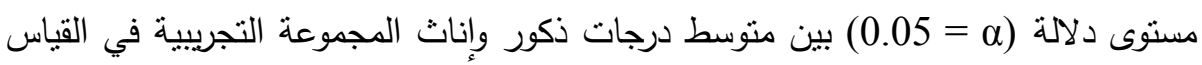
التتبعي على مقياس الوعي بالمسئولية البيئية لصالح الإناث. الحادي عشر: النتائج المتعلقة بالفرض الحادي عشر ومناقشتها: نوجد فروق ذات دلالة إحصائية عند مستوى دلالة (a) = 0.05) بين منوسط درجات ذكور واناث

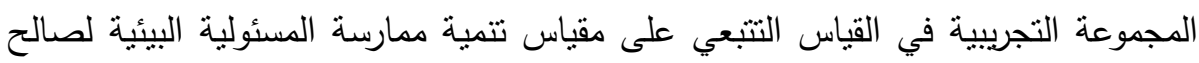

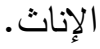
وللتحقق من صحة هذا الفرض تم استخدام اختبار" ت "لعينتين مستقلتين. 
جدول(ء 1 ): المتوسطات والانحرافات المعيارية وقيمة" ت "ومستوى الدلالة للتعرف إلى الفروق في بين متوسطات درجات الذكور والاناث في المجموعة التجريبية في القياس التتبعي لمقياس تتمية ممارسة المسئولية البيئية

\begin{tabular}{|c|c|c|c|c|c|c|c|}
\hline الاستدلال & دلالةتوي & قيمة t & الانحرافي & المتوسط & العدد & المجموعة & البيان \\
\hline \multirow{2}{*}{ دالة } & \multirow{2}{*}{0.000} & \multirow{2}{*}{5.344} & 7.257 & 106.35 & 20 & تجربيية & مقتمية \\
\hline & & & 13.913 & 125.1 & 20 & تتبعي اناثة & البسئولية \\
\hline
\end{tabular}

أظهرت نتائج الجدول السابق أن: وجود فروق في تتمية ممارسة المسئولية البيئية بين منوسط

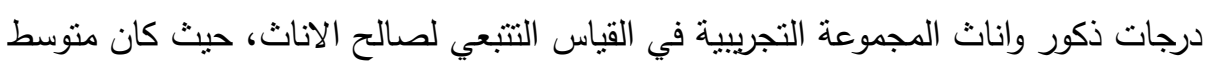
ذكور المجموعة التجريبية في القياس التتبعي (106.35) واناث المجموعة التجريبية في القياس التتبعي(125.10) ، وقيمة" ت (5.344) "عند مستوي معنوية(0.05) ، وهي بذلك

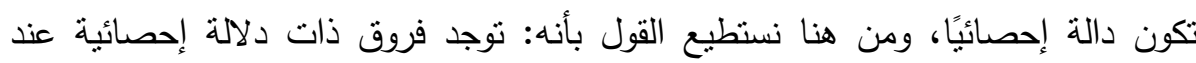

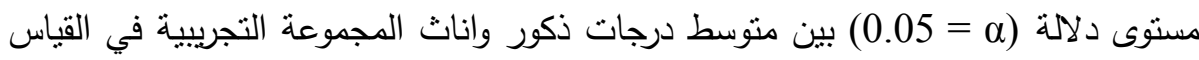
التتبعي على مقياس تتمية ممارسة المسئولية البيئية لصالح الإناث.

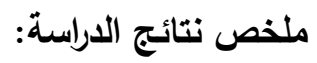
• قبول وجود فروق ذات دلالة إحصائية عند مستوى دلالة ( = 0.05) بين متوسط درجات أفراد المجموعة التجريبية و متوسط درجات أفراد المجموعة الضابطة في مقياس الوعي دلاسي

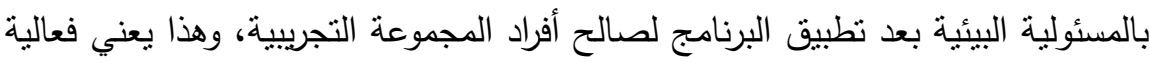
البرنامج الذي تم تطبيقه علي عينة الدراسة في الوعي بالمسئولية البيئية، وتحقيق الاستفادة لئه من نظرية التعلم الاجتماعي. • قبول وجود فروق ذات دلالة إحصائية عند مستوى دلالة ( = 0.05) بين متوسط درجات

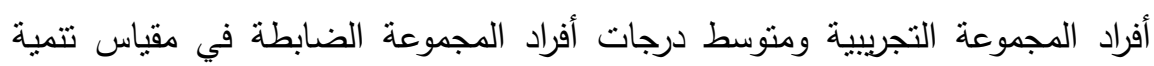

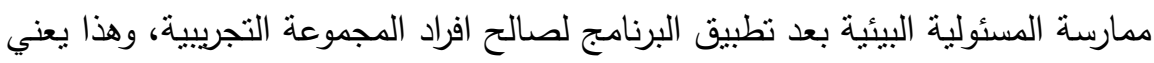
فعالية البرنامج الذي نم تطبيقه علي عبنة الدراسة في تتمية ممارسة المسئولية البيئية، وتطوير الوظيفة والدور لدي العينة التجربية وتحقق التوفق مع نظرية الدور لئرية 
قبول وجود فروق ذات دلالة إحصائية عند مسنوى دلالة (a = 0.05) بين متوسط درجات أفراد المجموعة التجريبية و متوسط درجات أفراد المجموعة الضابطة في مقياس دلاس العمل الاجتماعي بعد تطبيق البرنامج لصالح افراد المجموعة التجريبية، وهذا يعني فعالية

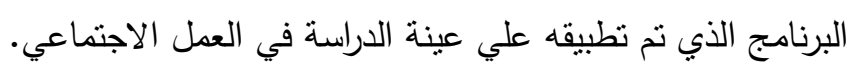
توجد فروق ذات دلالة إحصائية عند مستوى دلالة (a = 0.05) بين منوسط درجات ذكور

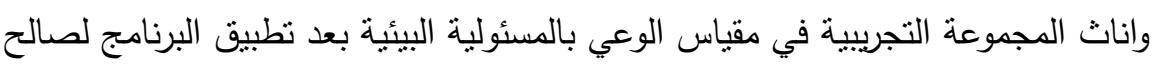
الاناث .وذلك ممثل لنظرية الدراسة في التأثز والاتصال. توجد فروق ذات دلالة إحصائية عند مستوى دلالة (a = 0.05) بين منوسط درجات ذكور

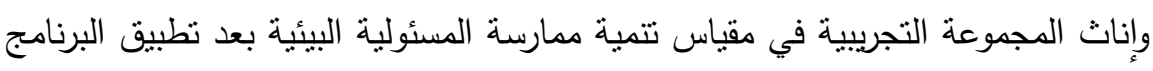

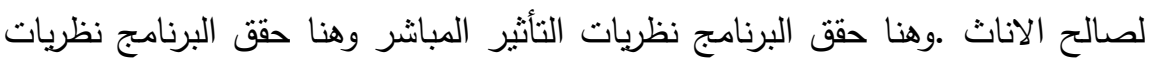

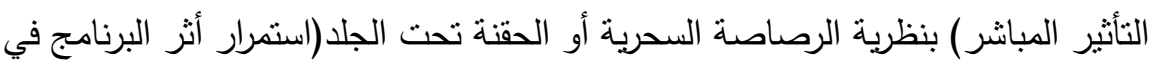

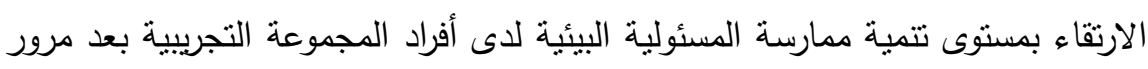
شهر من تطبيق البرنامج عليهر عل افرد العينة التجربية. توجد فروق ذات دلالة إحصائية عند مستوى دلالة (a = 0.05) بين منوسط درجات

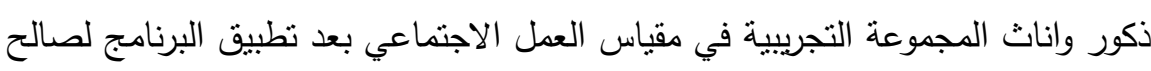
الاناث. توجد فروق ذات دلالة إحصائية عند مستوى دلالة (a = 0.05) بين متوسط درجات أفراد المجموعة التجريبية ومتوسط درجات أفراد المجموعة نفسها في القياسين البعدي والتتبعي

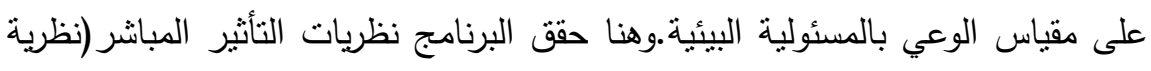
التعلم المعرفي (على افرد العينة التجربية). 


\section{الليوكيانيه}

إتاحة الفرصة أمام مساهمات الثباب المتطوع وخلق قيادات جديدة وعدم احتكار العمل

$$
\text { التطوعي على فئة أو مجموعة معينة. }
$$

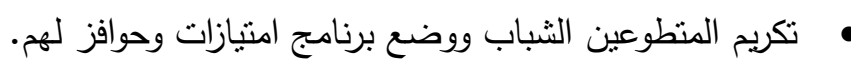

• • • •تشجيع العمل التطوعي في صفوف الثباب دهما كان حجمه أو شكله أو نوعه.

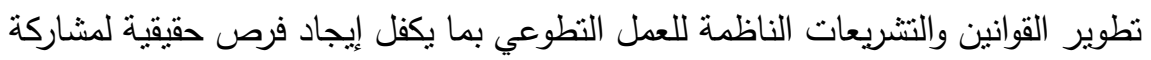

الثباب في اتخاذ القرارات المتصلة بالعمل الاجتماعي.

• إنشاء اتحاد خاص بالمتطوعين بشرف على تدريبهم وتوزيع المهام عليهم وينظم طاقاتهم. تشجيع الثباب وذلك بإيجاد مشاريع خاصة بهم تهدف إلى تتمية روح الانتماء والمبادرة

أن تمارس المدرسة والجامعة والمؤسسة الدينية والجمعيات الاهلية والاندية ومراكز الثباب

دوراً أكبر في حث الثباب على النطوع خاصة في العطل الصيفية.

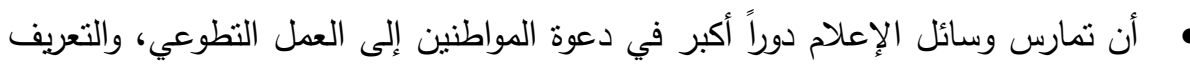

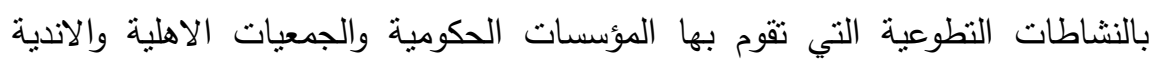
ومراكز الثباب.

\section{exloll}

القرآن الكريم: سورة الاعراف الآية: . 157

أحمد إبراهيم شلبي(1984): البيئة والمناهج الدراسية، الكويت، مؤسسة الخليج العربي،

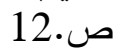

صفاء عبد العظيم محمد: التحديات التى تواجه ممارسة خدمة الجماعة فى تحقيق الرعاية

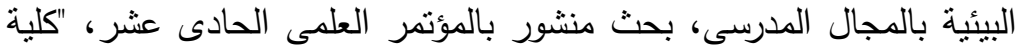

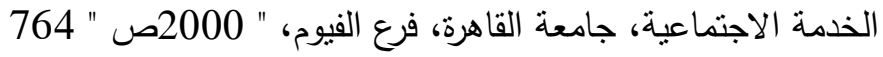

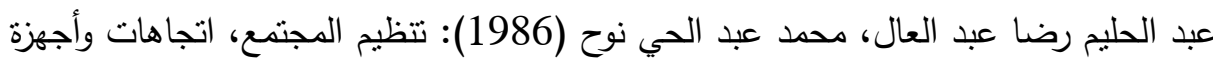

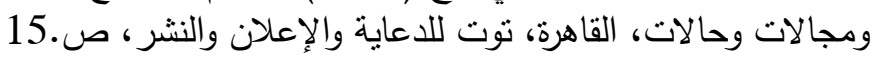




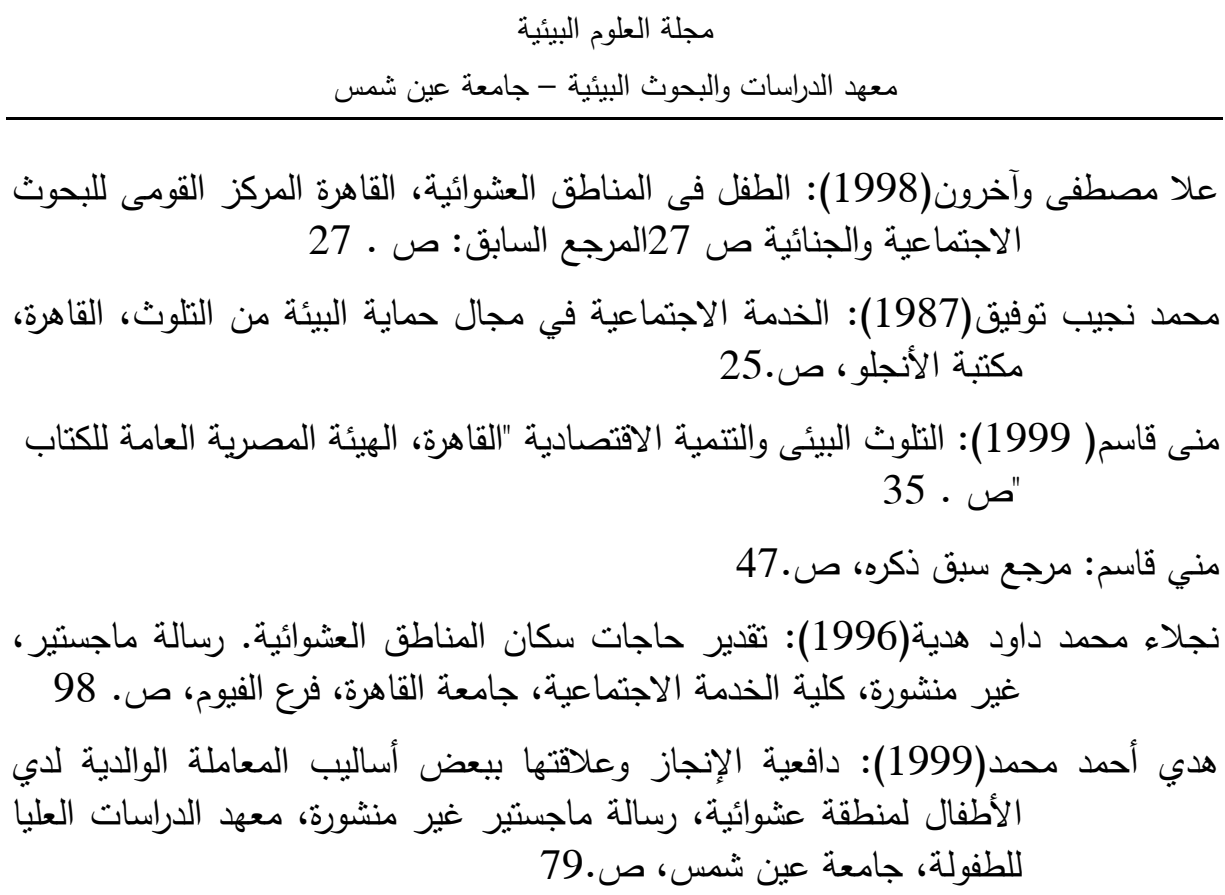

Uphoff، John Cohen and Arthur, A. Feasibility and application of rural development, New York: Cornell University, Rural Development Committee, Monograph No. 3, 1979.

Edmund M. Burke, Citizen participation strategy, Journal of the American Institution of Planners, Vol. 34, No. 5, Sep. 1968, pp. $287-294$.

Carme Melo-Escrihuela: 14 - Promoting Ecological Citizenship: Rights, Duties and Political Agency; Keele University, Chancellor's Building, Keele, Staffordshire ST5 5BG, UK; School of Politics, International Relations and Philosophy; Research Institute for Law, Politics and Justice; ACME Editorial Collective, 2008; pp120.122.

BINDU SHARMA: Contextualising CSR in Asia: Corporate social responsibility in Asian economies and the drivers that influence its practice, A research study commissioned by Lien Centre for Social Innovation، Social Insight Research Series, Printed and Typeset by Green Prints on، Indonesia, 2013, p15.

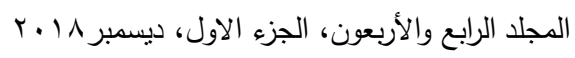




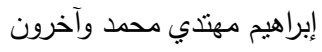

\title{
SOCI WORK AS AN APPROACH FOR DEVELOPING ENVIRONMENTAL RESPONSIBILITY AMONG SLUM AREAS RESIDENTS
}

\author{
Mohtady, I. M. ${ }^{(1)}$; Al-Atik, A. M. ${ }^{(1)}$ and Awad, M. I. ${ }^{(1)}$ \\ 1) Institute of Environmental Studies \& Research, Ain shams \\ university.
}

\begin{abstract}
The semi-experimental approach adopted by the study and the use of social work as an input to the development of environmental responsibility for the population of slums. This goal is achieved by the researchers through the social work program applied to a sample of males and women in the area of Kafr Tuhrmus and applied the kisses and past the sample consisting of (80) (40) Female 40 (40) Female (40) Male (40) Women, Measurement Tool We have adopted three measures in this study: the environmental awareness measure, the development of the practice of environmental responsibility, the measure of social work, Social Work Theory And the theories of communication in psychology and social science and theory of role and theory of social learning and theories of social participation in the development and strategy of social action wave of conservation on the environment and cognitive theory and behavioral, and the most important findings of the researchers is the success of social work in raising awareness of environmental responsibility for the sample To exercise environmental responsibility and to benefit from the social work program, there are statistically significant differences between the experimental group and the control group, and those differences in favor of the experimental group, thus accepting the assumption that: Very statistically significant differences at the level of significance $(0.05=\alpha)$ between the mean scores of the experimental group and the average score members of the control group in a measure of awareness of environmental responsibility after the application of the program for the benefit of
\end{abstract}

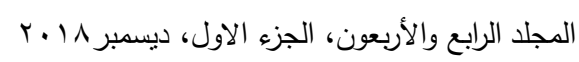


members of the experimental group. The results showed that there were differences in the awareness of environmental responsibility between the mean scores of males and females of the experimental group after applying the program for females. The mean of the experimental group was 50.95 and the experimental group was 60.50 and the value of $T$. was 3.784). 